\title{
A revision of the Early Jurassic ichthyosaur Hauffiopteryx (Reptilia: Ichthyosauria), and description of a new species from southwestern Germany
}

\author{
Erin E. Maxwell and Dirley Cortés
}

\begin{abstract}
Hauffiopteryx typicus is an Early Jurassic ichthyosaur species from Europe, for which geographically partitioned morphological variation between specimens from England and Germany has been described. We provide a complete anatomical description of the German material to address this taxonomical issue. We also identify and describe a new species of Hauffiopteryx from the southwest German Basin, Hauffiopteryx altera sp. nov., differring from $H$. typicus in the morphology of the arrangement of cranial elements surrounding the external nares. A phylogenetic analysis recovers the German and English material referred to $H$. typicus as sister taxa, suggesting that these are indeed conspecific. H. typicus forms a monophyletic group with $H$. altera and a specimen from the Pliensbachian of Switzerland previously referred to Leptonectes tenuirostris but consistent with $H$. typicus. We conclude that Hauffiopteryx represents a valid genus, defined by a set of synapomorphies from both the skull and postcranium. Parsimony analysis recovers Hauffiopteryx as sister taxon to Stenopterygius + Ophthalmosauridae.
\end{abstract}

Erin E. Maxwell. Staatliches Museum für Naturkunde, Rosenstein 1, 70191 Stuttgart, Germany, erin.maxwell@smns-bw.de

Dirley Cortés. Redpath Museum, McGill University, 859 Sherbrooke St. W., Montreal QC H3A 0C4, Canada. Smithsonian Tropical Research Institute, Balboa-Ancón 0843-03092, Panamá, Panamá.

dirley.cortes@mail.mcgill.ca

Keywords: Hauffiopteryx; new species; Posidonienschiefer Formation; Germany; Toarcian; Early Jurassic

Submission: 2 November 2018. Acceptance: 12 June 2020.

http://zoobank.org/041F166A-28FC-4ED6-AD7C-DF64EF4EF1A7

Maxwell, Erin E. and Cortés, Dirley. 2020. A revision of the Early Jurassic ichthyosaur Hauffiopteryx (Reptilia: Ichthyosauria), and description of a new species from southwestern Germany. Palaeontologia Electronica, 23(2):a31. https://doi.org/10.26879/937 palaeo-electronica.org/content/2020/3078-revision-of-hauffiopteryx 


\section{INTRODUCTION}

The Posidonienschiefer Formation (Posidonia Shale) of southwestern Germany is considered one of the classic Mesozoic marine fossil lagerstätte, and has yielded thousands of exceptionally preserved fish and reptile remains (Urlichs et al., 1994). The fossil marine reptiles, in particular, have garnered a great deal of research attention. The most abundant and best-preserved of these are the ichthyosaurs, represented in museum collections by hundreds of specimens including examples with fossilized soft-tissues, gastric contents, and embryos preserved inside the body cavity (Hauff, 1921; Böttcher, 1989, 1990). The first ichthyosaur formally named from the Posidonia Shale was Temnodontosaurus trigonodon, named over 175 years ago (Theodori, 1843), and the most recently erected species still regarded as valid were named almost 90 years ago (Stenopterygius uniter von Huene, 1931 and Hauffiopteryx typicus [von Huene, 1931]). Ongoing research has emphasized questions pertaining to paleobiology, including intraspecific variation (e.g., Maxwell, 2012a), ontogeny (e.g., Dick and Maxwell, 2015), diet (e.g., Dick et al., 2016), and prevalence of skeletal pathologies (e.g., Pardo-Pérez et al., 2019). The discovery of new species following so many years of intensive research effort was thought to be unlikely.

The monotypic genus Hauffiopteryx (Maisch, 2008 ) is the most recently named and least distinctive ichthyosaur genus from the Posidonienschiefer Formation. The genus has a convoluted history. Hauffiopteryx typicus (von Huene, 1931) was initially referred to Stenopterygius as S. hauffianus / S. hauffianus forma typica due to its small size and similarities in forelimb morphology (von Huene, 1922, 1931); the unusual morphology of the pelvic girdle was interpreted as an abnormality (McGowan, 1978). Maisch (2008) recognized Hauffiopteryx as distinct from Stenopterygius based on the small, round temporal fenestra, extensive gastralia, and medially unfused pelvic girdle. He considered Hauffiopteryx to be nested within Thunnosauria, potentially forming a sister group to Stenopterygius + Ophthalmosauridae. This hypothesis was supported by subsequent cladistic analyses (Fischer et al., 2016; Moon, 2017). However, Hauffiopteryx has also been recovered in a more basal position, as sister group to Thunnosauria (Ji et al., 2016).

Maisch (2008) initially identified seven specimens referable to Hauffiopteryx typicus: one from the Toarcian of the UK, five from southwestern
Germany, and one from Luxembourg. We were unable to examine the latter skull personally but consider most likely referable to the more abundant genus Stenopterygius based on the apparent exclusion of the prefrontal by the lacrimal from the posterior edge of the external nares (Godefroit, 1994: pl. 3a). Two additional specimens from the Toarcian of the UK were later referred (Caine and Benton, 2011). The specific referral of BRLSI M 1399, part of the original referred material cited by Maisch (2008), was later questioned following CTscanning and detailed description, as it failed to form a monophyletic group with $\mathrm{H}$. typicus in phylogenetic analysis (Marek et al., 2015). This raised questions of provincialism and endemism among Early Jurassic ichthyosaurs that can only be resolved by restudy of the German material.

In addition to the material from the Toarcian of Germany and the UK, a small skull from the Pliensbachian of Switzerland (NMO 26575) referred to Leptonectes tenuirostris was described as varying from the typical morphology observed in Hettangian-Sinemurian specimens of $L$. tenuirostris by a series of features such as small size, shorter rostrum, participation of the prefrontal in the external narial opening, and notching of the forefin elements (Maisch and Reisdorf, 2006). These characters are now known to differentiate Hauffiopteryx and Leptonectes, thus meriting reevaluation of the taxonomic affinities of NMO 26575. Problematically, L. tenuirostris was partially scored based on NMO 26575 in the analysis of Moon (2017), and possibly other analyses as well.

Here, we provide a complete anatomical description of Hauffiopteryx from the Southwest German Basin. We re-examined the five specimens cited by Maisch (2008), and included five additional specimens from the collections of the SMNS, GPIT, and the Werkforum Dotternhausen. This study led to the recognition of a second species of Hauffiopteryx from southwestern Germany, Hauffiopteryx altera sp. nov. We also reconsider the affinities of NMO 26575 from the Early Jurassic of Switzerland described as Leptonectes tenuirostris by Maisch and Reisdorf (2006), which shares many morphological similarities with $H$. typicus.

\section{MATERIAL}

We re-examined the five specimens cited by Maisch (2008) as referable to Hauffiopteryx typicus: GPIT 1491/4 (bed number $\varepsilon \|_{4}$, Holzmaden), MHH 9 (bed number $\varepsilon \|_{4 / 5}$, Holzmaden), SMNS $51552\left(\varepsilon \|_{3}\right.$, Zell unter Aichelberg), SMNS 80225 
$\left(\varepsilon \|_{4}\right.$, Schlierbach), and SMNS $81965\left(\varepsilon \|_{4}\right.$, Schlierbach). We also studied an additional six specimens that we considered to be referable to Hauffiopteryx based on the diagnosis of Maisch (2008): SMNS 81367 (a small skeleton in left lateral view lacking the pelvic girdle and anterior caudal region, from bed number $\varepsilon l_{4}$ of Schlierbach, Baden-Württemberg), SMNS 80226 (a partial skeleton in ventral view with pectoral girdle, gastralia and ribs preserved but lacking the hind limbs, from bed number $\varepsilon \|_{4}$ of Schlierbach, Baden-Württemberg), SMNS 81962 (an almost complete skeleton in ventral view, including a partial skull, pectoral girdle and limbs, from bed number $\varepsilon \|_{3}$, Ohmden), GPIT/RE/ 12905, a moderately compressed skull from an unknown locality and horizon of the Posidonienschiefer Formation, and FWD-129 (DotternhausenDormettingen, $\left.\varepsilon \|_{4 / 5}\right)$, a lightly compressed skull, pectoral girdle and anterior vertebral column preserved in a concretion, previously considered to be a juvenile of Eurhinosaurus longirostris (Jäger, 2005). We also restudied NMO 26575, a threedimensional skull and some associated postcranial elements from the upper Pliensbachian of Hauenstein, Switzerland, previously referred to Leptonectes tenuirostris but varying in several characteristics now more suggestive of Hauffiopteryx Maisch, 2008, such as small size and closely packed forelimb elements with anterior notches (Maisch and Reisdorf, 2006).

\section{Institutional Abbreviations}

BRLSI, Bath Royal Literary and Scientific Institution, Bath, UK; FWD, Werkforum, DotternhausenDormettingen, Baden-Württemberg, Germany; GPIT, Palaeontological Collections of Tübingen University, Tübingen, Germany; MHH, Museum Hauff, Holzmaden, Germany; NMO, Naturmuseum Olten, Switzerland; SMNS, Staatliches Museum für Naturkunde Stuttgart, Germany.

\section{SYSTEMATIC PALEONTOLOGY}

\author{
ICHTHYOPTERYGIA Owen, 1859 \\ ICHTHYOSAURIA Blainville, 1835 \\ PARVIPELVIA Motani, 1999 \\ HAUFFIOPTERYX Maisch, 2008
}

Type species. Hauffiopteryx typicus (von Huene, 1931)

Revised generic diagnosis. A small- to mid-sized ichthyosaur, 2-3 $\mathrm{m}$ in length, with relatively short and slender antorbital rostrum; slight overbite present (unlike Eurhinosaurus, Excalibosaurus in which a substantial overbite is present); prefrontal partici- pating in margin of external naris (unlike Eurhinosaurus, Leptonectes, Stenopterygius); nasals with a greater contribution to the dorsal midline of the rostrum anterior to the external narial opening than the premaxillae (unlike Stenopterygius); prefrontal with larger external exposure on dorsal skull roof than the postfrontal (unlike Stenopterygius); parietal foramen situated anterior to the supratemporal fenestra (situated at the same level as the anterior edge of the supratemporal fenestra in Stenopterygius); supratemporal fenestra small and circular in dorsal view (similar to Eurhinosaurus but unlike Stenopterygius); supratemporal palmate in posterodorsal view (similar to Eurhinosaurus, unlike Stenopterygius); teeth with smooth enamel (unlike Suevoleviathan); gastralia extending posteriorly to the thirty-fifth presacral vertebra (unique feature among Toarcian ichthyosaurs); rib tuberculum and capitulum widely separated in the dorsal region (unlike Temnodontosaurus, Suevoleviathan, Eurhinosaurus); glenoid end of scapula anteriorly expanded (unlike in Temnodontosaurus); coracoid with anterior notch, foramen between humerus, radius, and ulna absent (unlike Suevoleviathan, Temnodontosaurus trigonodon); anterior digit in both fore- and hindfins with notches on the anterior edge (unlike in Suevoleviathan); proximal limb elements angular and forming a tightly articulated mosaic; ischium and pubis thin and styloidal, fused laterally but widely separated medially (autapomorphic); fibula larger than the tibia; hindfin digits converging distally.

\section{Hauffiopteryx typicus (von Huene, 1931) Figures 1-5}

Lectotype. GPIT 1491/4; a complete skeleton with partial preserved soft-tissue outline in left lateral view. GPIT 1491/4; a complete skeleton with partial preserved soft-tissue outline in left lateral view (Figure 1A).

Geographical distribution. Baden-Württemberg, Germany; IIminster (UK) (Maisch, 2008); Solothurn, Switzerland (see discussion for details).

Stratigraphic distribution. Late Pliensbachian, margaritatus Zone; lower Toarcian, tenuicostatum Zone, semicelatum Subzone-serpentinum Zone,

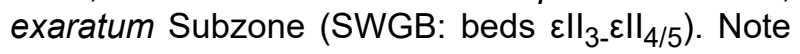
that according to the specimen label, SMNS 51552 originates from bed $\varepsilon \|_{3}$, rather than $\varepsilon \|_{2}$ as stated elsewhere (Maisch, 2008). Peak abundance occurs in $\varepsilon \|_{4}$, where material referred to Hauffiopteryx represents a substantial percentage of all small ichthyosaurs recovered (Maxwell and Vincent, 2016). 


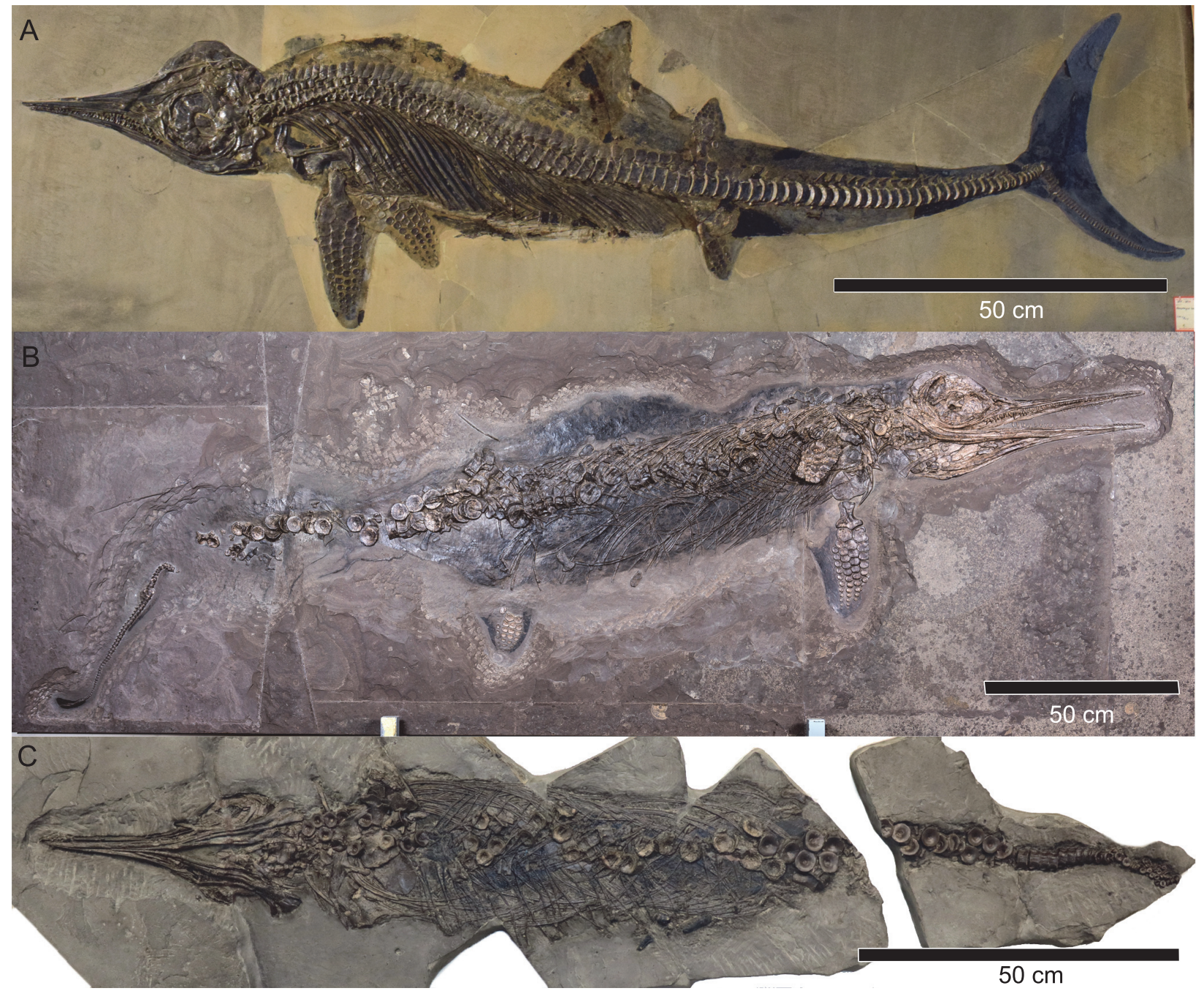

FIGURE 1. Hauffiopteryx typicus. A, lectotype, GPIT 1491/4; B, SMNS 51552; C, SMNS 80226. Part 1B @ SMNS / M. Wahler.

Emended diagnosis. Hauffiopteryx typicus can be distinguished from other species of Hauffiopteryx by a triradiate lacrimal forming the posterior border of the external narial opening, deepest lateral exposure of the maxilla located ventral to the posterior half of the external narial opening, a large, rounded orbit, and nasals with pronounced dorsal inflection at the anterior orbital margin.

Referred specimens. Of the material examined, GPIT 1491/4, GPIT/RE/12905, MHH 9, SMNS 51552, and SMNS 80226 can be confidently referred to $H$. typicus (Figures 1-3). The English material referred to Hauffiopteryx is also consistent with H. typicus, as is NMO 26575 from the Pliensbachian of Switzerland (see discussion for details).

\section{DESCRIPTION}

The description is based on GPIT 1491/4, GPIT/RE/12905, MHH 9, SMNS 51552, and SMNS 80226; selected measurements can be found in Appendix 1. Variation in the shape of the posterior premaxilla and anterior lacrimal in GPIT/RE/12905 is attributed to differences in preservation and intraspecific variation between this and the other skulls; these variants are clearly noted in the description. The English and Swiss material is excluded from the description.

Premaxilla. The premaxilla is gracile and dentigerous, decreasing rapidly in depth anteriorly (Figure $2 \mathrm{~A}-2 \mathrm{C}$ ). Posteriorly, a subnarial process extends ventral to the anterior portion of the external narial opening. A robust, extensive supranarial process is absent; however, in GPIT/RE/12905 a slender process is present (Figure $3 A$ ). It is shorter than the 

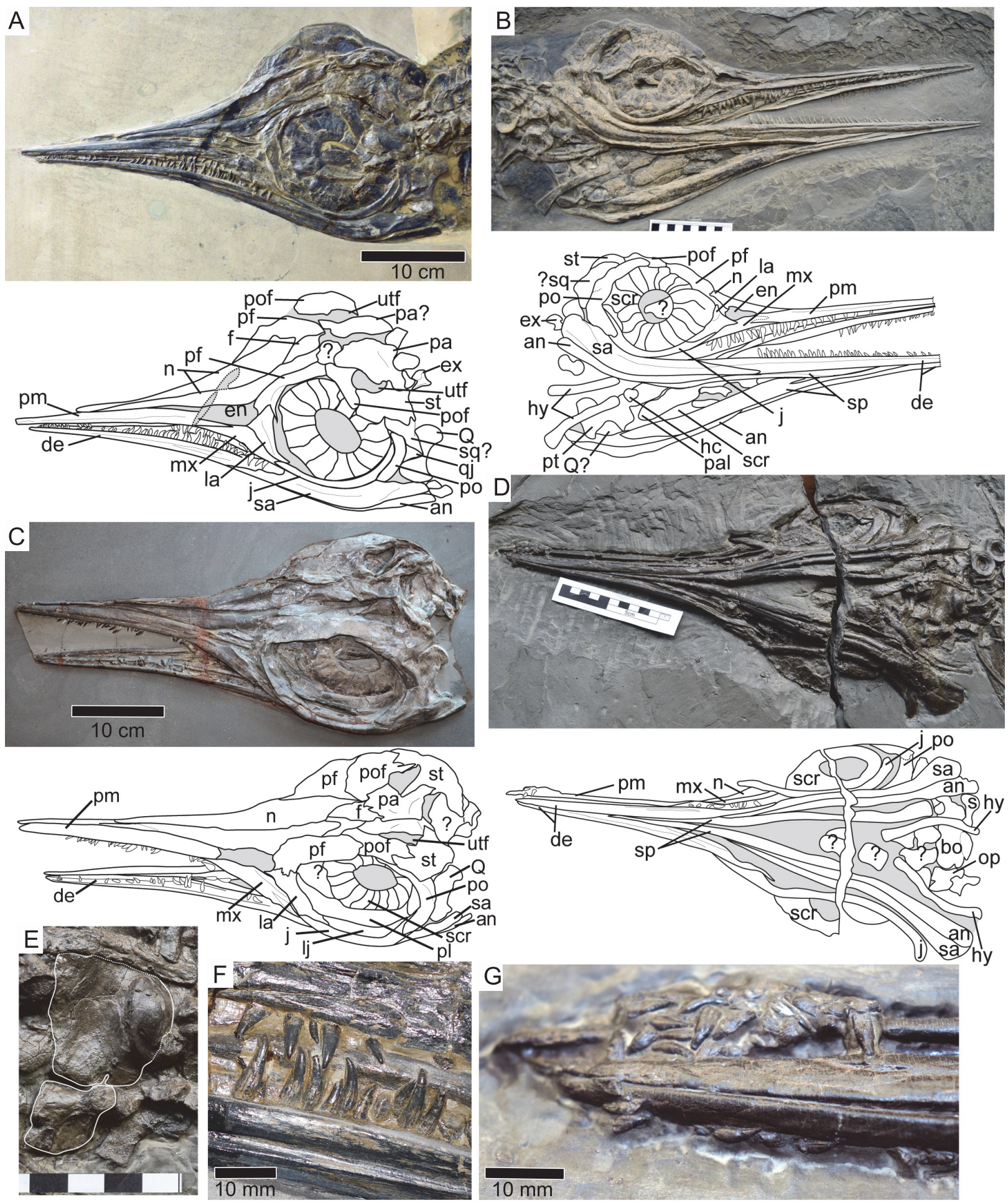

FIGURE 2. Hauffiopteryx typicus, cranial morphology. A-G, overview of cranial morphology. A, lectotype, GPIT 1491/ 4; B, SMNS 51552; C, MHH 9; D, SMNS 80226. E, basioccipital in ventral view (SMNS 80226); F, maxillary and posterior dentary teeth (GPIT 1491/4); G, anterior mandible with displaced teeth (SMNS 80226). Scale bars in cm (parts B, D, E). Abbreviations: an, angular; bo, basioccipital; de, dentary; hc, hyoid corpus; hy, hyoid element; en, external narial opening; ex, exoccipital; f, frontal; j, jugal; la, lacrimal; lj, lower jaw; mx, maxilla; n, nasal; op, opisthotic; pa, parietal; pal, palatine; pf, prefrontal; pl, palate; pm, premaxilla; po, postorbital; pof, postfrontal; pt, pterygoid; Q, quadrate; qj, quadratojugal; sa, surangular; scr, sclerotic ring; sp, splenial; sq, squamosal; st, supratemporal; s, stapes; utf, supratemporal fenestra. 

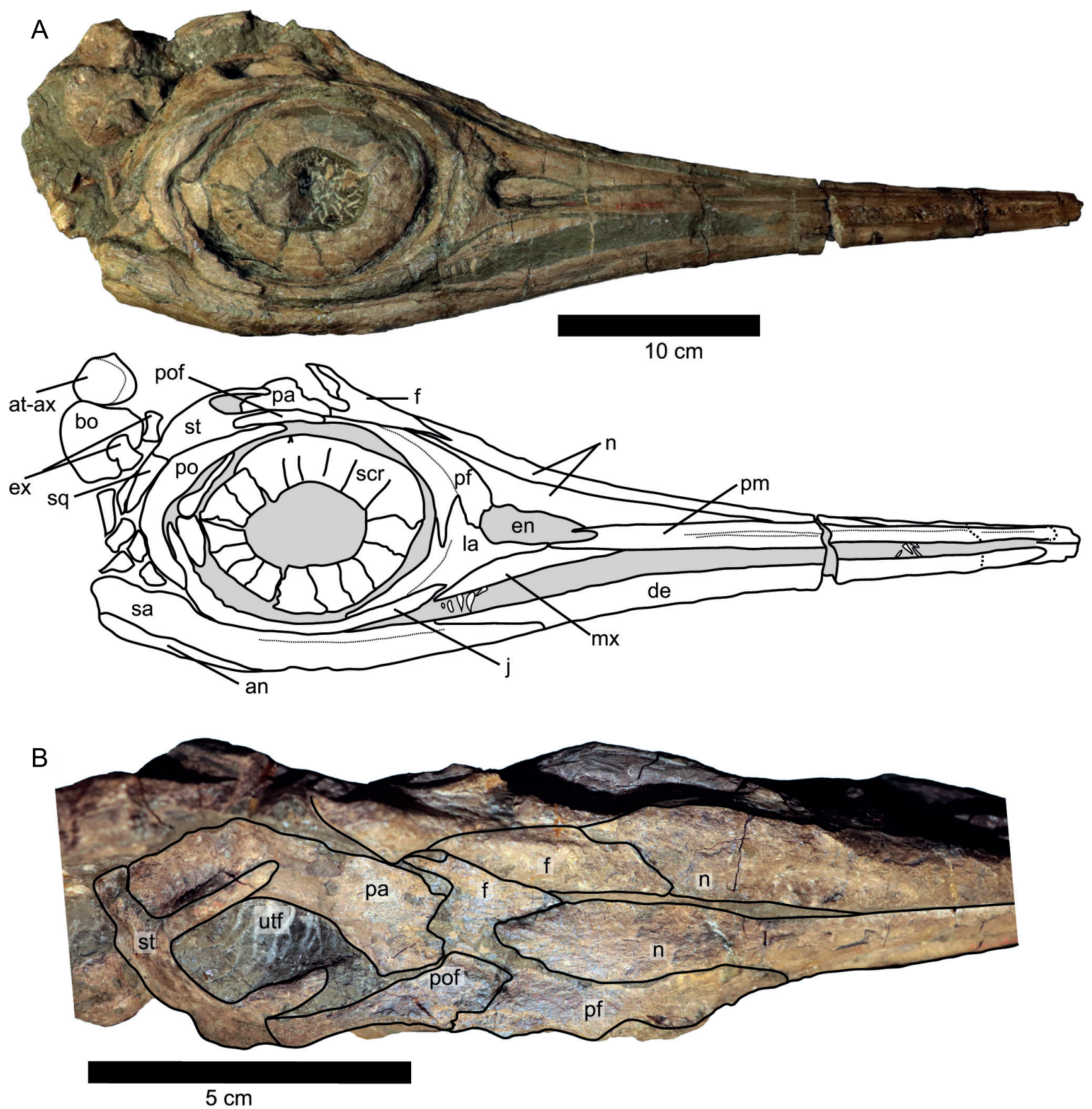

FIGURE 3. Hauffiopteryx typicus, cranial morphology of GPIT/RE/12905. A, lateral view; B; dorsal view of posterior skull roof. Abbreviations: an, angular; bo, basioccipital; de, dentary; en, external narial opening; ex, exoccipital; f, frontal; j, jugal; la, lacrimal; mx, maxilla; n, nasal; pa, parietal; pf, prefrontal; pm, premaxilla; po, postorbital; pof, postfrontal; sa, surangular; scr, sclerotic ring; sq, squamosal; st, supratemporal; utf, supratemporal fenestra.

subnarial process, and extends less than one quarter of the length of the external narial opening. Although apparently absent in GPIT 1491/4, MHH 9 , and SMNS 51552, the quality of preservation of this region in these specimens does not preclude the erosion of such a delicate bony structure through either taphonomic processes or preparation. The premaxillary fossa is deepest at its midpoint, becoming rapidly shallower posteriorly. The premaxillary rostrum is short in all diagnostic material, with prenarial segment ratios of $\sim 0.49$ (GPIT/ $\mathrm{RE} / 12905$ ), 0.48 (MHH 9), 0.42 (SMNS 80226), and $\sim 0.37$ (GPIT 1491/4). The rostral tips (both premaxillary and mandibular) of SMNS 51552, often cited as an example of Hauffiopteryx with a long rostrum (Maisch, 2008), are of problematic authenticity; as preserved the prenarial segment = 0.46 . 
Maxilla. The maxilla in $H$. typicus is short, and does not extend more than a few millimeters anterior to the external narial opening in lateral view (Figures 2A-2C, 3A). The dentigerous portion continues posterior to the external narial opening. The maxilla forms the ventral edge of the external narial opening in most specimens, but is excluded in GPIT/RE/12905 by contact between the premaxilla and lacrimal. An ascending process posterior to the narial opening is absent. The orbital process of the maxilla is moderately elongated, but does not reach the orbital mid-point and is shorter than the suborbital process of the lacrimal. Anteriorly, the maxilla is dorsally overlapped by the premaxilla. Posteriorly, it contacts the jugal and lacrimal.

Nasal. The nasals are exposed dorsally over approximately two thirds of the antorbital rostrum (Figure 2A, 2C). The presence of an internasal foramen could not be evaluated in the extremely compressed material, but an internasal depression was certainly present medial to the external nares. The nasal forms the dorsal edge of the external narial opening and contacts the prefrontal at the posterodorsal edge of the external narial opening. On the dorsal skull roof, the nasals contact the prefrontal laterally and the frontal posteriorly. A small, superficial contact between the nasal and the postfrontal, overlapping the prefrontal, may occur posterolaterally (Figure $2 \mathrm{C}$ ).

Lacrimal. The lacrimal is small, with a very short subnarial process in most skulls (Figure 2A-2C). It usually participates in only the posteroventral corner of the external narial opening. However, in GPIT/RE/12905 the subnarial process of the lacrimal is slender but elongate, extending over more than half the total length of the external narial opening to contact the subnarial process of the premaxilla (Figure $3 \mathrm{~A}$ ); we consider this to be intraspecific variation, as documented in other Early Jurassic ichthyosaur species (see discussion). The suborbital process of the lacrimal articulates ventrally with the jugal and is relatively elongate. The suborbital process is separated from the lateral portion of the element by a ridge, forming part of the circumorbital area. The ascending process contacts the prefrontal via an interdigitating suture, and does not contact the nasal.

Jugal. The jugal is a relatively slender, deeply bowed element. It is overlapped by the postorbital posterolaterally, excluding the ventral postorbital from the posterior edge of the orbit (Figures $2 \mathrm{~A}-2 \mathrm{C}$, $3 A)$. The dorsal process of the posterior jugal is narrow and mediolaterally compressed, lacking pronounced anteroposterior expansion. Anteriorly, the jugal narrows, and slots between the lacrimal and maxilla. It does not reach the external narial opening.

Prefrontal. The prefrontal forms a large narial process, and participates extensively in the posterior portion of the external narial opening (Figure 2A2C). It forms approximately $50 \%$ of the dorsal orbital margin. The prefrontal extends medially to contact the frontal, but may be overlapped by processes of the postfrontal and the nasal.

Frontal. The frontals are relatively narrow and slightly convex, tapering anteriorly. They form the external anterior and lateral margins of the parietal foramen (Figure 2A, 2C).

Parietal. The parietal forms approximately half of the anterior edge of the supratemporal fenestra (Figure 2A, 2C). The medial process of the supratemporal excludes the parietal entirely from the posteromedial edge of the fenestra, best seen in GPIT/RE/12905. The interparietal suture is straight. A weak ridge separates the posterior lamina from the dorsal surface of the parietal. A weakly developed ridge lateral to the parietal foramen runs anterolaterally to posteromedially.

Postfrontal. The postfrontal forms the anterolateral margin of the supratemporal fenestra (Figure $2 \mathrm{~A}, 2 \mathrm{C}$ ). It interdigitates with the supratemporal along the posterolateral margin of the supratemporal fenestra. The postfrontal overlaps the postorbital along the dorsal edge of the orbit.

Postorbital. The postorbital makes up the posterior edge of the orbit (Figure 2A-2D). It is a narrow semi-lunate element. It contacts the squamosal posteriorly, and the supratemporal dorsally, with a very small anterodorsal contact with the postfrontal. Ventrally, the postorbital is excluded from the orbital margin in all specimens by the ascending process of the jugal.

Supratemporal. The supratemporal is large, forming a posterior lamella with radiating ridges, giving it a scalloped appearance in external view (Figure $2 \mathrm{~A}, 2 \mathrm{C}$ ). These ridges correspond to the anteromedial and anterolateral processes of the anterior ramus, as well as to small medial and lateral processes of the medial ramus. A well-developed ventral ramus is present. It is not significantly longer than the medial or lateral processes.

Squamosal. The squamosal is well-preserved only in GPIT/RE/12905 (Figure 3). It is exposed on the posterolateral skull and is roughly triangular in shape, with a descending process posterior to the postorbital. Dorsally it contacts the supratemporal. Quadratojugal. The ventral portion of the quadratojugal is preserved in the lectotype (Figure 2A). In 
external view, it appears to be excluded from contact with the jugal by the postorbital, but this could be due to taphonomic displacement. The ventral edge is thickened for articulation with the quadrate. Quadrate. The posterolateral portion of the quadrate is exposed in both MHH 9 and in GPIT 1491/4 (Figure 2A, 2C). The quadrate is laterally concave. The ventral articular end is thickened, and a small occipital lamella is present.

\section{Braincase}

Basioccipital. The basioccipital is not well-preserved in the lectotype. It is best-exposed in SMNS 80226 and GPIT/RE/12905 in ventral view (Figure 2D-2E). It has an extensive extracondylar area (ECA), with the portion ventral to the condyle being wider than the lateral ECA. The ventral extracondylar area is anteromedially concave, with small lateral tubers. The condyle itself bears a notochordal pit and is clearly offset from the extracondylar area. Opisthotic. The right opisthotic is preserved in SMNS 80226 (Figure 2D-2E), in what is interpreted as anterior view. The medial edge bears a notch interpreted as the vagus foramen. The paroccipital process is short. The anterior surface of the opisthotic ventral to the paroccipital process is concave, clearly setting off the process.

Stapes. An element thought to be the left stapes is preserved in SMNS 80226 (Figure 2D). The lateral shaft is slender, and the quadrate articulation is not expanded. The ventral surface of the shaft is more concave than the dorsal surface. The medial head is robust.

Exoccipitals. Exoccipitals are preserved in SMNS 51552 as well as in the lectotype (Figure 2A-2B). These are short, squat elements forming the lateral edges of the foramen magnum. The medial edge is concave. The number of foramina cannot be assessed with confidence.

Prootic, supraoccipital, parabasisphenoid. None of these elements could be identified with confidence in the specimens determined to be diagnostic at the specific level.

\section{Palate}

The palate of $H$. typicus is best-exposed in SMNS 51552 (Figure 2B; see also Maisch, 1998a: fig. 3).

Pterygoid. The pterygoid is preserved in ventral view. The quadrate ramus is preserved posteriorly and is offset from the palatal ramus by a pronounced constriction. The lateral process of the quadrate ramus is more slender than the medial process. The palatal ramus bears a robust postpalatine process.

Palatine. The palatine is present in SMNS 51552; however, due to poor preparation little can be said about either its anatomy or position.

Vomer. The vomer could not be identified in the specimens determined to be diagnostic at the specific level.

\section{Mandible}

A small overbite is consistently present (Figure 2A, 2C-2D, 2G); this does not appear to become more pronounced in larger specimens. The lower jaw is bowed ventral to the orbit.

The dentaries are fine and pointed anteriorly, and make up approximately $45 \%$ of the length of the mandibular symphysis (Figure 2D, 2G). In lateral view, the dentary fossa is well-developed and deep, but disappears towards the anteriormost tip of the mandible (Figure 2A-2B). Aulacodont tooth implantation is seen throughout the dentary, with the alveolar groove narrowing significantly towards the anterior tip (Figure $2 \mathrm{C}$ ).

The splenials form the medial surface of the mandible and a substantial portion of the mandibular symphysis. They are most robust at the posteriormost symphysis, thinning rapidly anteriorly in ventral view (Figure 2B, 2D). Posteriorly, they also attenuate in ventral view, but more slowly. At their posterior ends, the splenials are concealed in ventral view in articulated specimens by the medial curvature of the angular, which forms a shelf.

The posterior lateral lower jaw is made up of the surangular and angular. The lateral exposure of the former is much greater than that of the latter. The angular forms the ventral edge of the lower jaw, extending from the retroarticular process posteriorly to approximately the level of the external narial opening. The surangular extends further anteriorly than the angular. Ventral to the orbit, the surangular forms a well-developed surangular fossa. A strong ridge and ventral depression is developed on the lateral surangular contribution to the retroarticular process, presumably indicating a point of muscle attachment.

Prearticular. The prearticular is preserved in SMNS 80226, forming a fine splint of bone in ventral view posterior to and medially overlapped by the splenial.

Articular. The articular is not well-exposed in any of the diagnostic material.

Dentition. The teeth are small and acutely pointed, with the crowns typically showing some lingual curvature. The enamel is smooth (Figure 2F, 2G). 

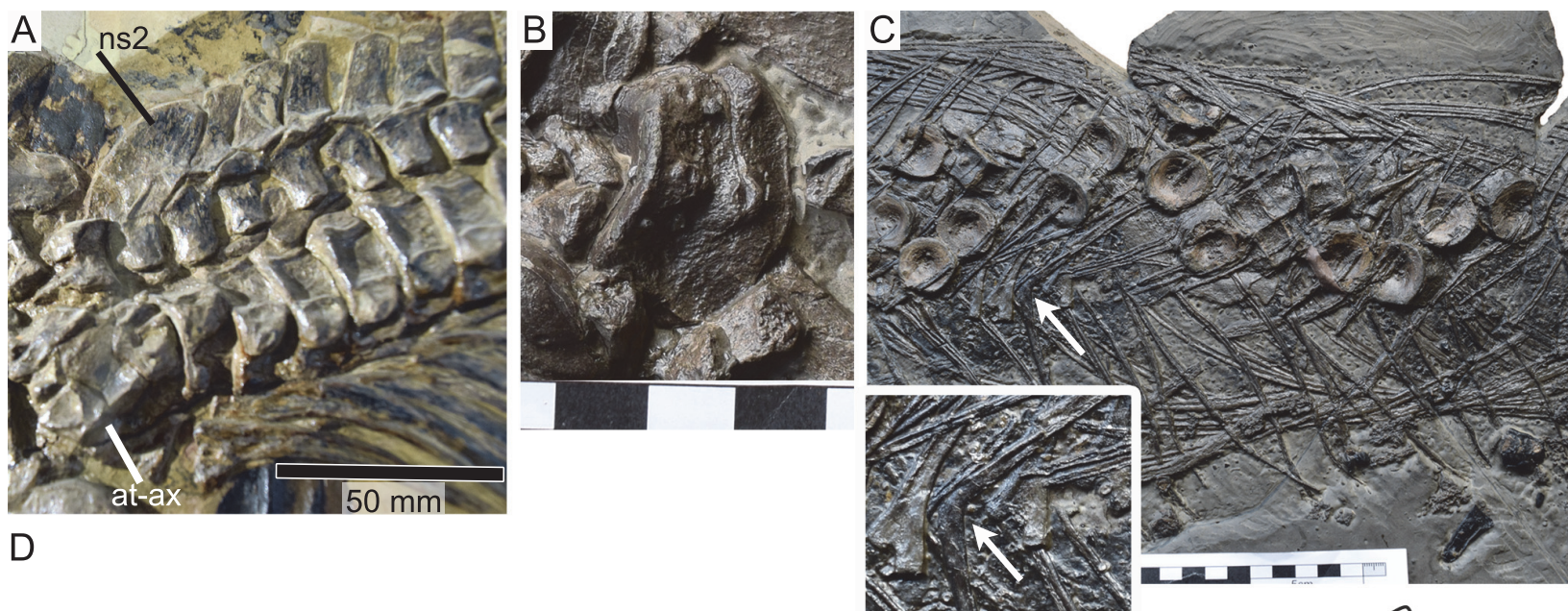

D

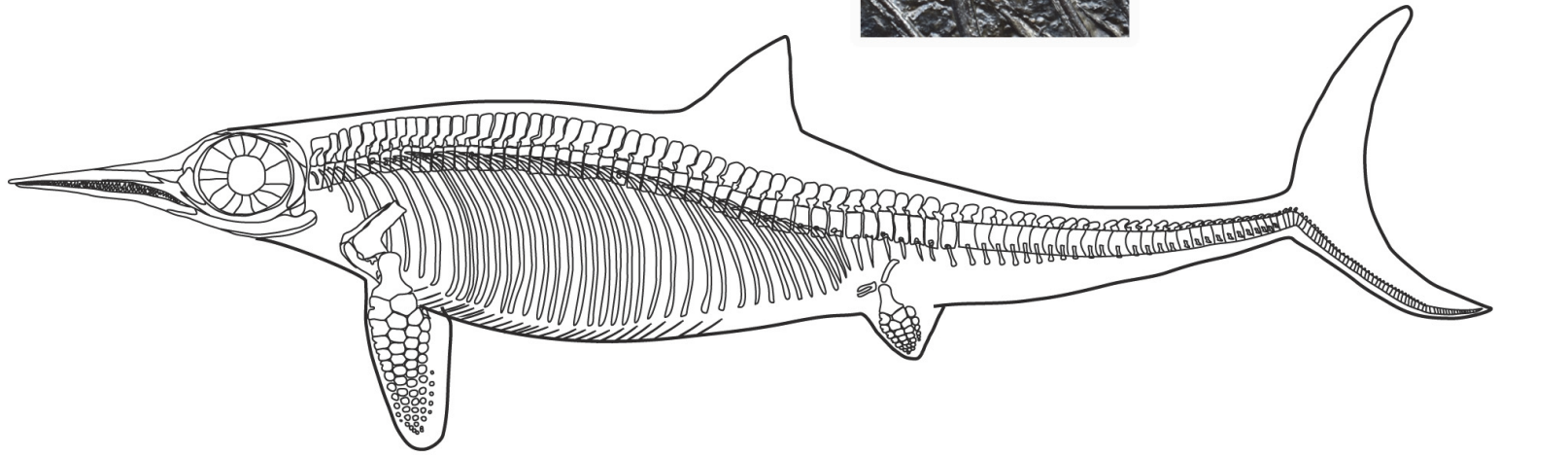

FIGURE 4. Postcranial morphology of Hauffiopteryx typicus. A, anterior neural spines of the lectotype GPIT 1491/4, note the broad axial neural spine of the same height as the neural spine of C3 but twice as wide. B, Fused atlas-axis complex (SMNS 80226); C, gastralia in the mid-dorsal region of SMNS 80226, the arrow indicates the boomerangshaped medial element (see also inset); D, reconstruction of Hauffiopteryx typicus; the shape and position of the dorsal and caudal fins are based on the lectotype. Anterior is to the left in all parts. Scale bars in cm (parts B, C). Abbreviations: at-ax, atlas-axis complex; ns2, neural spine (axis).

Crown height decreases notably towards the anterior tips of the jaws: in MHH 9, for instance, midpremaxillary tooth crowns are approximately 4.5 $\mathrm{mm}$ in height, whereas the anteriormost dentary crowns are approximately $2 \mathrm{~mm}$ in height. The tooth roots show strong apicobasal ridges indicative of plicidentine; large quantities of cellular cementum appear to be absent.

Sclerotic ring. The sclerotic ring in the GPIT 1491/ 4 preserves approximately 16-17 ossicles (poor preservation makes an exact count impossible); 17 ossicles are also preserved in SMNS 51552 and GPIT/RE/12905. In all three specimens, the sclerotic ring appears to fill the orbit, although taphonomic breakage and distortion are moderate to severe in all skulls (least so in GPIT/RE/12905).

Hyoid apparatus. Paired ceratobranchials are ossified but often compressed, making it difficult to assess morphology. Shape differs widely between specimens, with the ceratobranchials being later- ally concave in SMNS 51552 (Figure 2B) and laterally convex in SMNS 80226 (Figure 2D). An ossified hyoid corpus is present in SMNS 51552 (Figure 2B).

\section{Postcranium}

Vertebral column. 45-46 presacral vertebrae, 81 preflexural vertebrae, $\sim 3$ apical vertebrae, and $>55$ postflexural vertebrae are preserved in the lectotype, becoming very small towards the end of the caudal fin (Figure 1A). There is some uncertainty in presacral count because the last vertebra with unfused di- and parapophyses is posterior to the position of the pelvic girdle. The atlas and axis are preserved in SMNS 80226 and are exposed in lateral view (Figure 4B). They are completely fused, with a suture persisting on the lateroventral surface. The remaining presacral centra are round in articular view and are deeply amphicoelous. Cervical centra are small, and dimensions increase pos- 

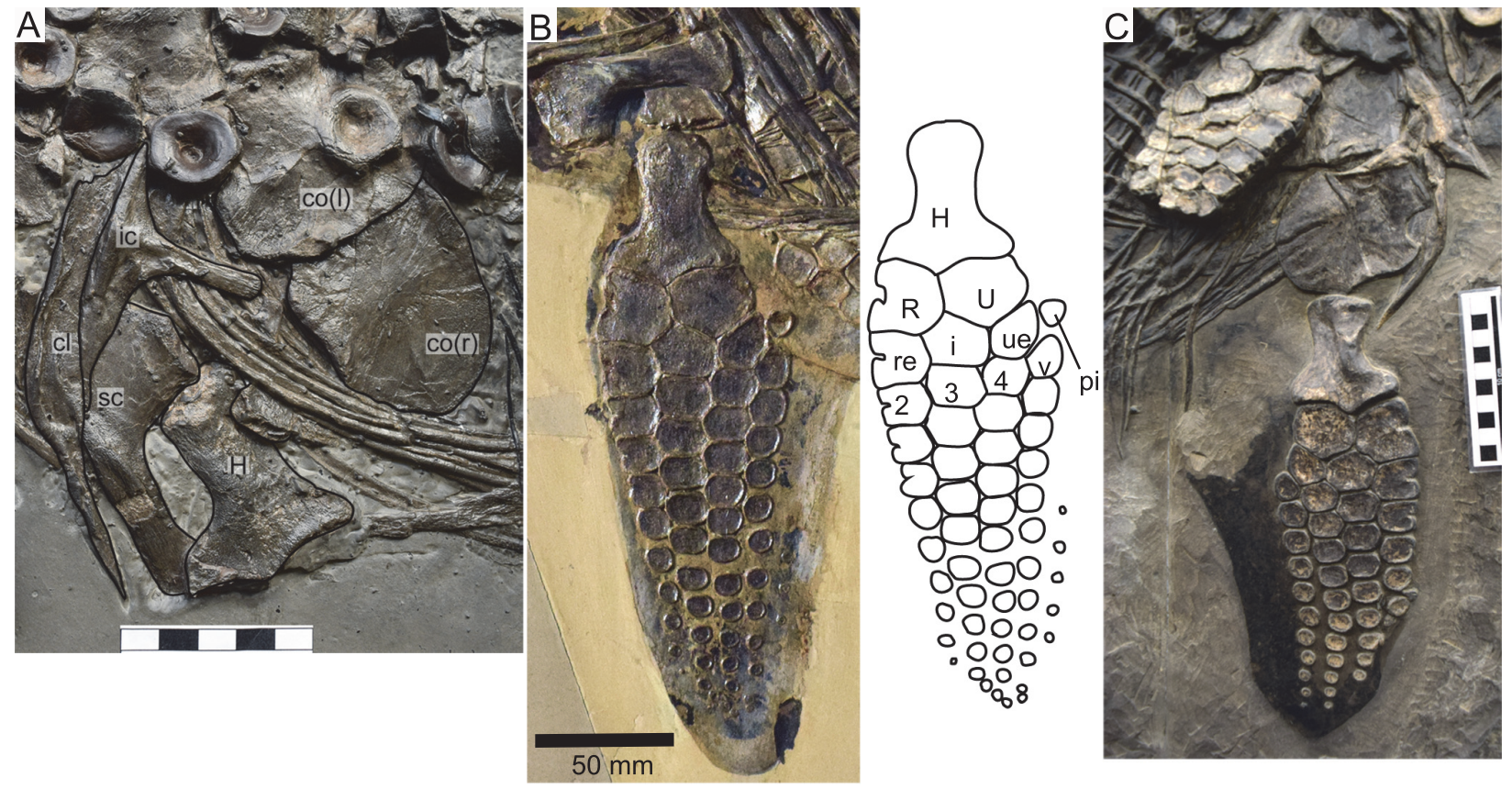

FIGURE 5. Hauffiopteryx typicus, pectoral girdle, and forelimb. A, pectoral girdle and humerus in ventral view (SMNS 80226); B, left forelimb in dorsal view (lectotype GPIT 1491/4); C, coracoids and left forelimb in ventral view (SMNS 51552). Scale bars in cm (parts A, C). Abbreviations: 2-4, distal carpals; cl, clavicle; co ( $r / l)$, right and left coracoids; $H$, humerus; i, intermedium; ic, interclavicle; pi, pisiform; R, radius; re, radiale; sc, scapula; U, ulna; ue, ulnare; v, metacarpal V.

teriorly. Separate di- and parapophyses are present in all dorsal vertebrae. Apophyses begin to shift to a mid-centrum position anterior to the tail bend. Apophyses are absent in the apical centra and all postflexural vertebrae. The vertebral column is gently curved along its length, with the points of inflection located in the anterior dorsal region and mid-preflexural region.

In the lectotype, the axial neural spine is much broader than more posterior neural spines at its base, but tapers dorsally (Figure 4A). A substantial facet for the atlantal neural spine is preserved on its anterolateral surface. The atlantal spine itself is not preserved. The anterior dorsal neural spines are rectangular, but become broader and rounded in the posterior $2 / 3$ of the vertebral column (Figures $1 A, 4 D)$. Posterior to the pelvic girdle, neural spines become T-shaped, and lose articulation with each other. "Extra-neural processes" (sensu McGowan, 1992), as previously described in Stenopterygius, are present ventral to the posterior end of the dorsal fin and also on several more anterior vertebrae. Although positioned dorsal to the ossified neural spines, these lack any visible connection with the underlying skeletal tissues.

Ribs and gastralia. The cervical ribs are somewhat bicapitate, but the tuberculum and capitulum are less deeply separated than in the dorsal ribs (e.g., Figure 4A, 4C). Cervical and dorsal ribs are deeply grooved on the anterior and posterior surfaces. Caudal ribs are small, holocephalous, and paddle-like. Posterior to the apical vertebrae, ribs are absent - the presence of extensive soft-tissue preservation suggests that this is not an artefact. Chevrons are absent throughout the caudal skeleton.

Gastralia are relatively robust. They are long and thin, tapering at either end. There are two gastralial elements per side. In SMNS 80226, gastralia from the right and left sides are fused, forming a single dorso-ventrally flattened and slightly anteroposteriorly expanded boomerang-shaped bone along the midline (Figure 4C). However, this specimen also shows signs of callus development on many gastralia (Pardo-Pérez et al., 2019); it is unclear whether the formation of a median element may have been caused by trauma rather than representing normal morphology.

Body outline. The dorsal and caudal fins are preserved in the lectotype (Figure 1A). The dorsal fin is triangular in outline, located in the posterior half of the dorsal region and terminating anterior to the pelvic girdle. The caudal fin is semi-lunate in outline, and is symmetrical, with a very high aspect ratio and a strongly concave posterior edge. However, the degree to which preparation may have 
enhanced this shape is uncertain. The vertebral column extends into the distalmost tip of the ventral lobe.

Pectoral girdle and forelimb. The interclavicle is T-shaped, with the transverse bar being longer than the posterior stem. The posterior edge of the transverse bar is medially broader than at its lateral ends (Figure 5A). The clavicles are wing-like, tapering laterally, and medially broad (Figure 5A, $5 \mathrm{C})$. The coracoids are large, anteroposteriorly longer than proximodistally wide (Figure 5A, 5C). A small anterior notch is present. The scapular facet is much smaller than the glenoid contribution. A medial facet for the scapula appears to be absent. The scapula itself is divided into a medial blade and a lateral shaft (Figure 5A, 5B). The medial blade is anteriorly expanded, but a well-developed acromion process is absent. The coracoid facet is smaller than the glenoid contribution.

The humerus is relatively elongate, with the distal end greatly expanded relative to the proximal end (Figure 5). A well-developed humeral head is present only in the lectotype (Figure 5B); in all of the referred specimens the proximal humerus is rather flattened. The lectotype is the only specimen in which the humerus is exposed in dorsal view; unfortunately it is also the most strongly compressed specimen. The dorsal process is small, if present. The deltopectoral crest is robust, located close to the anterior edge and extending over more than half of the total length of the humerus (Figure $5 \mathrm{~A}, 5 \mathrm{C})$. The distal humerus bears a flattened, anteriorly directed facet on its leading edge ("tubercle" of Moon, 2017). Two distal facets are present, for articulation with the radius and ulna. The ulnar facet is larger than the radial facet.

All referred specimens show a similar forelimb configuration, in which the radius, radiale, distal carpal 2, and metacarpal II bear notches on their anterior surfaces (Figure 5B, 5C). In most specimens, the first phalanx of digit II is also notched anteriorly. The radius articulates posteriorly with the ulna, and distally with the radiale and intermedium. The ulna articulates distally with the intermedium and ulnare. A small pisiform posterior to the ulnare is present only in the lectotype (Figure 5B). The paddle is four digits wide; in the lectotype, a series of very small accessory ossicles lies posterior to digit $\mathrm{V}$. The posterior two digits (IV and $\mathrm{V}$ ) are the longest, with $\sim 10$ phalanges. Proximal limb elements are polygonal and tightly packed, whereas more distal elements are rounded and widely spaced. Based on the preserved soft tissue outline, the flipper was elongate and tapering, with digit II positioned close to the anterior edge.

Pelvic girdle and hind limb. The ilium is not wellpreserved in any of the referred specimens. In SMNS 80226, the element inferred to be the ilium is straight, shorter than the ischium and pubis (Figure $6 \mathrm{~A}$ ). The pubis is slender, being straight medially and posteriorly curving laterally to fuse with the ischium. Its medial end appears to be medially flattened. The ischium is the largest element in the pelvic girdle. It is thickened laterally and is triangular in cross-section, with a flat anterior surface. The medial end is also slightly anteroposteriorly expanded, and is gently rounded.

The femur is wider distally than proximally. The proximal end is strongly convex. The dorsal process is pronounced and more rounded (Figure 6B-6D). The ventral process is narrower, and extends further distally than the dorsal process (Figure 6A). There are two distal facets, for articulation with the tibia and fibula. The tibial facet is smaller than the fibular facet.

The hind fins are short and rounded (Figure 6B-6E). There are three elements in the zeugopodial row: the tibia, fibula, and a large pisiform that appears to give rise to a postaxial digit (in the sense that all elements in the digit are ossified and decrease in size from proximal to distal). The tibia is smaller than the fibula. The tibia and next three distal elements are notched anteriorly. The astragalus is positioned between the distal tibia and fibula. There are four digits in the metatarsal row, assuming that the posterior digit discussed above can be homologized with the 'true' digits. As discussed by Maisch (2008), the digits converge distally and so are of equal length. There are only approximately 4-5 phalanges per digit.

Hauffiopteryx altera sp. nov. Figures 7-8 zoobank.org/A567A292-2A58-495A-839F-FF8382B49479

v. 2005 Eurhinosaurus longirostris (Mantell, 1851): Jäger, p. 29, fig. 23.

Holotype. Holotype and only referred specimen FWD-129; a skull and partial postcranium preserved in a calcareous concretion (Figures 7-8; see Table 1 for selected measurements). The bones on the right side of the skull remain in articulation; those on the left side of the skull have suffered some taphonomic displacement.

Etymology. The specific epithet is derived from the Latin altera, which means different from/other and refers to the anatomical divergence from the type species, $H$. typicus.

Geographical distribution. Dotternhausen-Dormettingen, Baden-Württemberg, Germany. 

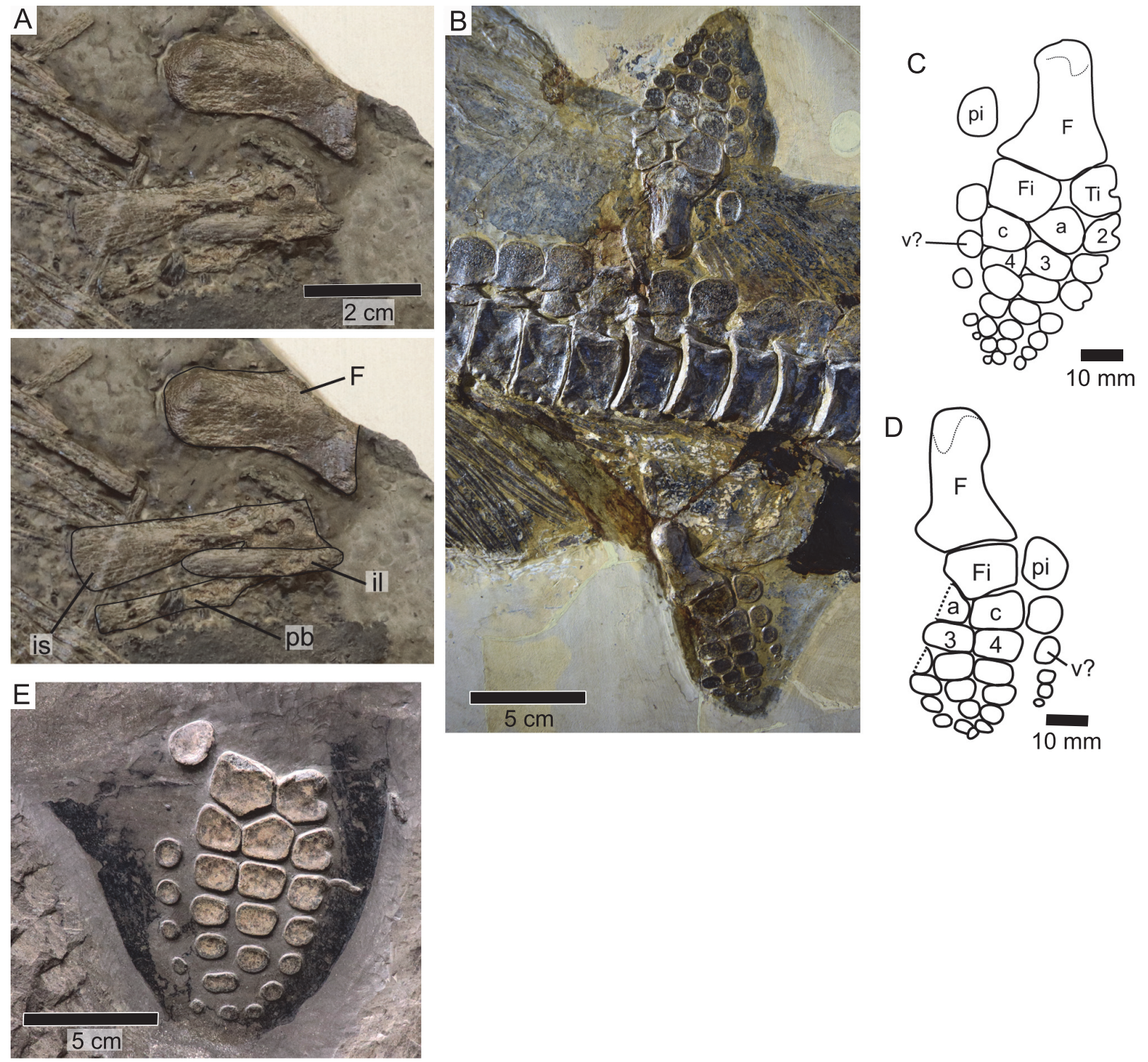

FIGURE 6. Hauffiopteryx typicus, pelvic girdle and hind limb. A, proximal left femur and pelvic girdle (SMNS 80226). $B$, pelvic girdle and hind limbs in dorsal view (lectotype GPIT 1491/4); C-D, interpretive drawings of hind limbs of same. E, hind limb of SMNS 51552. Abbreviations: 2-4, distal tarsals; a, astragalus; c, calcaneum; F, femur; Fi, fibula; il, ilium; is, ischium; pi, pisiform; pb, pubis; Ti, tibia; v?, putative metatarsal V; note the homology issues regarding both digit $\mathrm{V}$ and distal tarsal 2 in Hauffiopteryx and many other parvipelvians.

Stratigraphic distribution. Posidonienschiefer Formation, lower Toarcian, serpentinum Zone, exaratum Subzone (SWGB: bed $\varepsilon \|_{4 / 5}$ ).

Diagnosis. Hauffiopteryx altera differs from $H$ typicus in: deepest lateral exposure of the maxilla located posterior rather than ventral to the external narial opening; broad, triangular lacrimal excluded from the external narial opening by the descending process of the prefrontal; nasals extending further posteriorly on dorsal skull roof; dorsal exposure of prefrontal substantially greater than that of postfrontal.

\section{DESCRIPTION}

\section{Skull}

Premaxilla. The premaxilla has been broken and deformed anteriorly (Figure 7). Posteriorly, it is narrow and straight with a deep premaxillary fossa. A supranarial process is absent. The posterior tip of the premaxilla overlaps the maxilla almost to the 


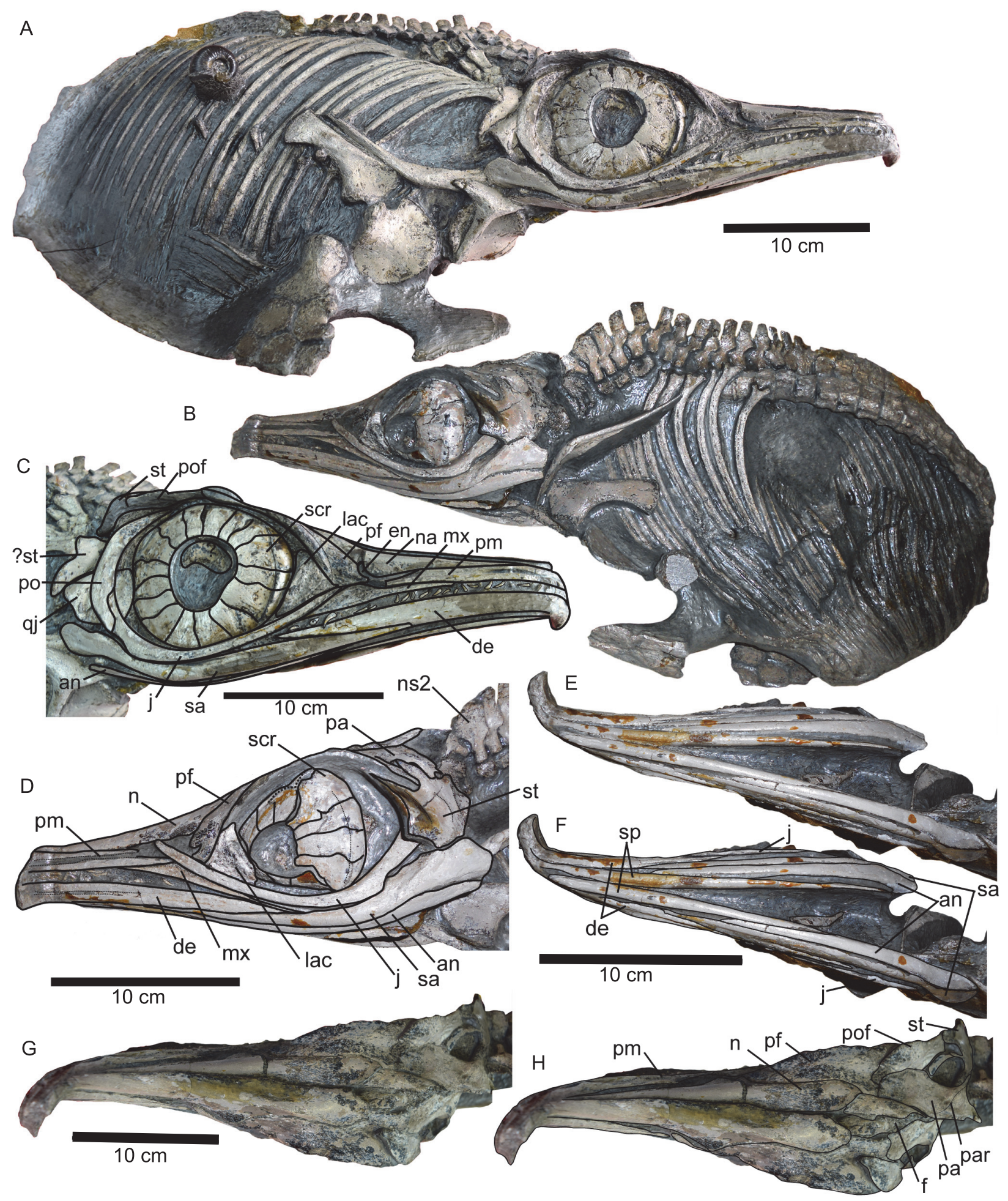

FIGURE 7. Hauffiopteryx altera, sp. nov., holotype FWD-129. A, B, right and left lateral views; C, D, interpretation of the cranial sutures in lateral view; $E$, $F$, ventral view of skull with interpretation; $G, H$, dorsal view of skull with interpretation. Abbreviations: an, angular; de, dentary; en, external narial opening; f, frontal; j, jugal; lac, lacrimal; mx, maxilla; $\mathrm{n}$, nasal; ns2, neural spine (axis); pa, parietal; par, parietal ridge; pf, prefrontal; pm, premaxilla; po, postorbital; pof, postfrontal; qj, quadratojugal; sa, surangular; scr, sclerotic ring; sp, splenial; st, supratemporal. 
A
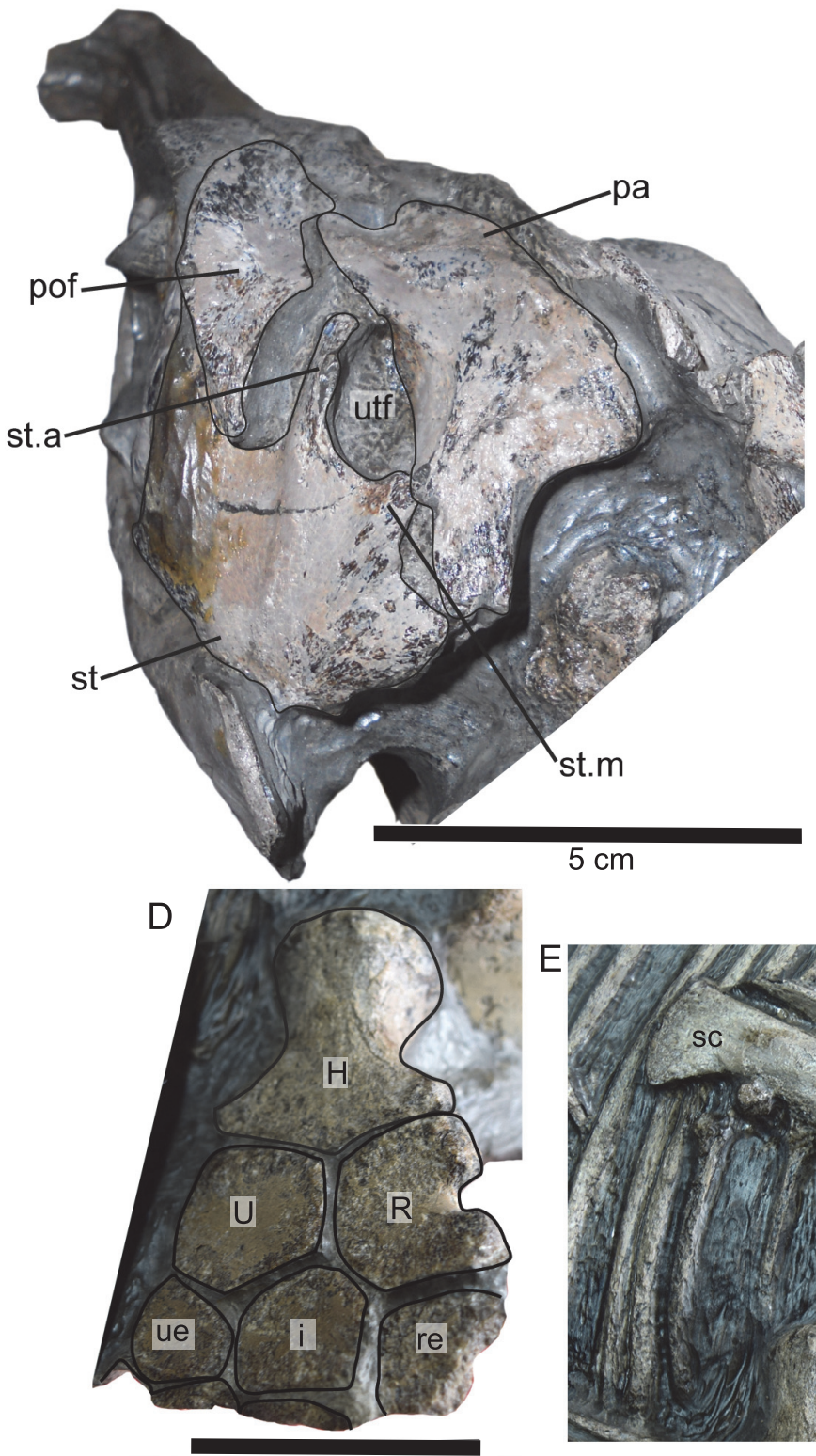

$5 \mathrm{~cm}$
B
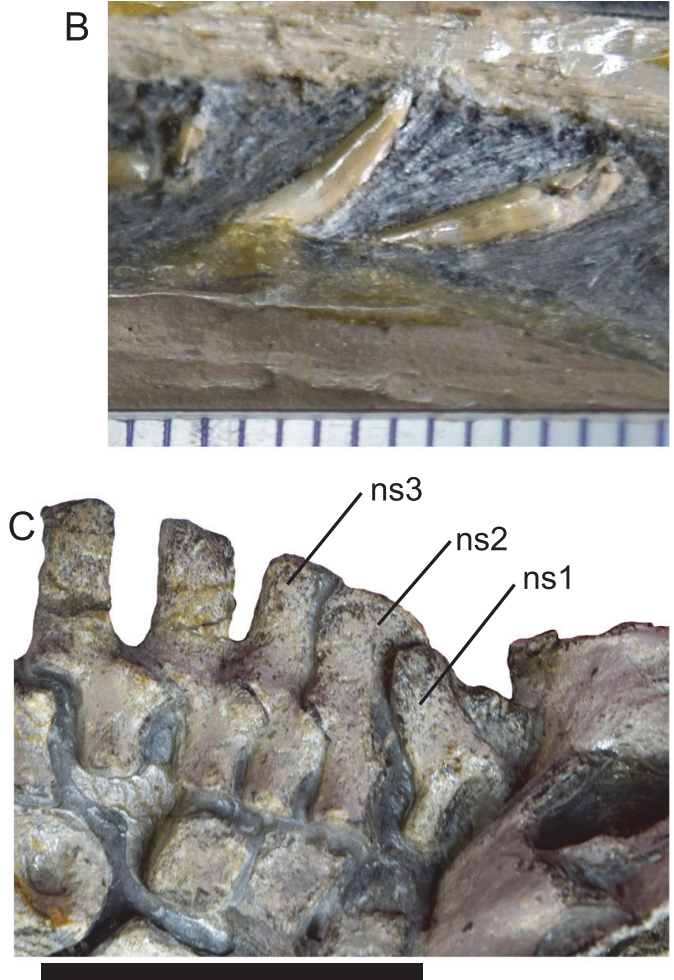

$5 \mathrm{~cm}$

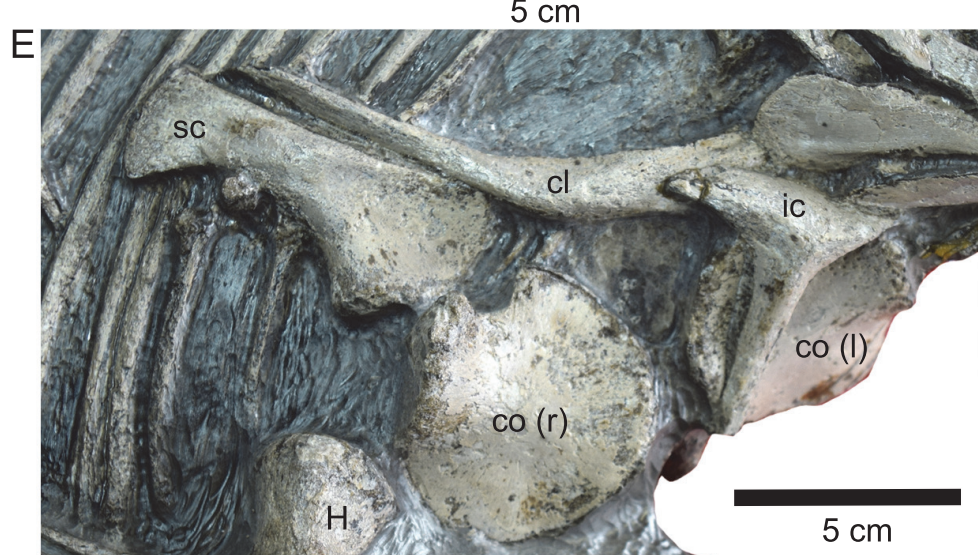

FIGURE 8. Hauffiopteryx altera, sp. nov., holotype FWD-129. A, left dorsal temporal region, illustrating the palmate morphology of the supratemporal; B, premaxillary and dentary teeth illustrating the thin, smooth enamel; scale bar is in $\mathrm{mm}$; $\mathrm{C}$, anterior neural arches, note the size and shape differentiation between the neural spines of the atlas, axis, and more posterior vertebrae; D, proximal right forelimb in dorsal view; $E$, pectoral girdle in external view. Abbreviations: cl, clavicle; $\mathrm{co}(\mathrm{r}) / \mathrm{co}(\mathrm{I})$, right and left coracoids; $\mathrm{H}$, humerus; i, intermedium; ic, interclavicle; ns1, neural spine (atlas); ns2, neural spine (axis); ns3, neural spine (C3); pa, parietal; pof, postfrontal; R, radius; re, radiale; sc, scapula; st, supratemporal; st.a, medial process of the anterior ramus of the supratemporal; st.m, medial ramus of the supratemporal; U, ulna; ue, ulnare; utf, supratemporal fenestra.

midpoint and forms the anteroventral edge of the external nares.

Maxilla. The maxilla has a small contact with the ventral edge of the external narial opening, and extends less than one narial length anterior to the nares (Figure 7C-7D). It is deeper posteriorly than anteriorly. Its deepest point in lateral view contacts the anteroventral tip of the prefrontal at the posterior edge of the narial opening (Figure 7C). The ventral edge of the maxilla is long and straight and posteriorly extends only to the anterior edge of the orbit on the right-hand side, being overlapped dorsally by the jugal; on the left the suborbital process 
TABLE 1. Hauffiopteryx altera sp. nov., selected measurements (in mm) of FWD-129 (holotype).

\begin{tabular}{lcc}
\hline \multicolumn{1}{c}{ Measurement } & & \\
\hline Total preserved length & 590 & \\
Lower jaw & $\begin{array}{c}\text { (preserved } \\
\text { length) }\end{array}$ & \\
Maxilla & 92 \\
Posterior lower jaw to & 200 & \\
symphysis & & Width \\
& Length & 85 (height) \\
Orbit (right) & 96 & 38.5 (height) \\
Sclerotic aperture & 35.5 & 79 (height) \\
Sclerotic ring & 88 & 32 (proximal) \\
Humerus (right) & 46 & 41 (distal) \\
& & 25 \\
Radius (right) & 26 & 25 \\
Ulna (right) & 26 & 50 \\
Coracoid (right) & 59 & 23 (distal) \\
Scapula (right) & 71 & \\
& & \\
\hline
\end{tabular}

is exposed in lateral view and is very long, extending to the orbital midpoint.

Nasal and external narial opening. The external narial opening is $25 \mathrm{~mm}$ long (right-hand side). It is simple in shape, with a small posterodorsal notch (Figure 7C). In lateral view, the dorsal surface of the nasal has a weak dorsal inflection anterior to the orbit. The ventral edge of the nasal is deflected ventrally at the level of the external narial opening, and the nasal forms a small ventrolateral shelf dorsal to the posterior narial opening. The nasals are relatively narrow anteriorly, but become broader at the level of the orbit, and are relatively limited in posterior extent. In dorsal view, the right and left nasals diverge posteriorly, creating a $V$-shaped contact with the frontals. An internasal depression is present, and an internasal foramen is possibly present (Figure 7G-7H); the dorsal surface of each nasal is strongly convex. The nasal contacts the frontal posteriorly and prefrontal laterally.

Lacrimal. The lacrimal is excluded from the external narial opening in lateral view by the prefrontal (Figure 7C-7D). The lacrimal is a blocky element, narrowing anteriorly with a scalene triangle shape in lateral view; it contacts the prefrontal dorsally and the jugal ventrally. The suborbital process is short. The lacrimal does not contact the maxilla but converges with the jugal and the prefrontal anterior to the orbit and posterior to the narial opening. The lacrimal is anteroposteriorly longest at the level of the sclerotic aperture. The anterior tip of the lacrimal appears to be laterally deflected relative to the posterior part of the element, and the portion making up the circumorbital area is more strongly curved than the ventral edge of the element.

Jugal. The jugal is deeply bowed ventral to the orbit. It tapers anteriorly between the lacrimal and the maxilla, extending past the anterior edge of the circumorbital area. Posteriorly, the jugal is overlapped by the postorbital. The posterior ramus of the jugal is offset approximately $120^{\circ}$ from the ventral one, being wider and shorter with a flat external surface. The dorsal margin is evenly curved, whereas the ventral one forms a small projection at the posteroventral orbit (Figure 7C-7D).

Prefrontal. The prefrontal is a large element forming the anterodorsal orbital rim, with an anterior process reaching the external narial opening and forming its entire posterior edge. The prefrontal contacts the anterior tip of the jugal (Figure 7C7D). The body of the prefrontal is massive, being as broad in dorsal view as the nasal (Figure 7G$7 \mathrm{H})$. In lateral view, the anterior portion forming the orbital rim tapers ventrally and is considerably thinner than the posterior portion. Posterodorsally, the prefrontal contacts the postfrontal, parietal, and frontal (medially).

Frontal. The frontals are small and elongate, and are dorsally convex. They enclose the parietal foramen medially (Figure 7G-7H). The frontal is overlapped by the nasal (anteriorly), prefrontal (laterally), and parietal (posteriorly).

Parietal. The parietal has an irregular external surface (Figures 7G-7H, 8A). There is a depression between the medial supratemporal fenestra and interparietal suture, possibly corresponding to the area lateral to the sagittal eminence. The parietal shelf is large and oriented dorsally. The parietal ridge is weakly developed. Posterolaterally, the parietal has a small process, which contacts the supratemporal posteriorly. The parietal contacts the prefrontal (anteriorly), postfrontal (laterally), and frontal (anterolaterally).

Postfrontal. The postfrontal is anteroposteriorly elongate and has an anteromedial depression in dorsal view (Figures 7G-7H, 8A). Its posteromedial edge encloses the supratemporal fenestra and is overlapped by the supratemporal. The postfrontal becomes narrower anteriorly until it forms a point that overlaps the prefrontal anteriorly. In lateral view, the postfrontal is slightly arched and forms the dorsolateral edge of the posterior skull. The postfrontal extends as far anteriorly as the anterior 
parietal but is narrower than the latter, and extends anteriorly to the orbital midpoint (Figure 7C).

Postorbital. The postorbital forms the posterior edge of the orbit (Figure 7C). A small dorsal lamella appears to be present. In lateral view, the postorbital is wider than the jugal, but still narrow in relation to its height. The ventral postorbital overlaps the jugal, and is excluded from the posteroventral edge of the orbit by the latter. The dorsal postorbital is overlapped by the postfrontal. The dorsal and ventral ends of the postorbital are tapered, forming a semilunate shape.

Supratemporal. The supratemporal is posteriorly broad and slightly convex dorsally (Figures 7G-7H, $8 \mathrm{~A})$. A long anterior ramus excludes the postfrontal from the lateral edge of the supratemporal fenestra. The supratemporal is anteroposteriorly shorter than mediolaterally broad. A descending ramus is present but not clearly exposed. The supratemporal bears four ridges radiating from the posterolateral corner (Figure 8A); we use the term 'palmate' to refer to this morphology.

Quadratojugal. The quadratojugal is small, triangular, and articulates along its entire anterior edge with the postorbital (Figure 7C).

Orbit. The sclerotic ring consists of 16 plates. It is $88 \mathrm{~mm}$ long and $79 \mathrm{~mm}$ high; the sclerotic aperture is $38.5 \mathrm{~mm}$ high and $35.5 \mathrm{~mm}$ long and is elliptical in shape. The orbit is $96 \mathrm{~mm}$ long and $85 \mathrm{~mm}$ high and is teardrop-shaped in lateral view when the circumorbital area is also considered. The orbit is bordered by the prefrontal, postfrontal, postorbital, jugal, and lacrimal (Figure 7C-7D).

\section{Quadrate and Palate}

There is an element covered by the postorbital in right lateral view, which may be the quadrate based on position and shape.

The palate is not exposed.

\section{Mandible}

Dentary. The dentary is a robust element that tapers anteriorly (Figure 7C-7D). The anterior tip is missing. The posterior end forms a thin point, articulating ventrally with the surangular at the level of the anterior orbit. The dentary becomes progressively deeper ventral to the external narial opening until it makes up the entire lateral surface of the lower jaw. The dentary is slightly convex in lateral view along the entire occlusal edge. The dentary fossa is present along its lateral surface.

Angular. The angular is short and does not extend as far anteriorly as the surangular in lateral view (Figure 7D). In ventral view, the posterior end of the angular is slightly expanded with rounded edges, while the anterior end tapers to a sharp point, and disappears from ventral view at approximately the level of the maxilla, just posterior to the symphysis (Figure 7E-7F). The ventral edge of the angular is not strongly curved in lateral view. However, the lower jaw appears slightly bowed ventral to the orbit (Figure 7C-7D).

Splenial. Posteriorly, the splenial contacts the medial surface of the angular, becoming broader in ventral view as the angular thins (Figure 7E-7F). The splenial is thin and convex in ventral view. The posterior end is elongated and pointed. The anterior end is not preserved. The broadest point of the splenial in ventral view occurs at the posterior end of the mandibular symphysis.

Surangular. The surangular is an elongate and large element that forms a significant part of the posterior end of the lower jaw (Figure 7C-7D). It is strongly curved ventral to the orbit. The posterior end is broad and ovate in lateral view, with a sinusoidal dorsal margin, formed in part by a small coronoid process. The anterior contact with the dentary is elongate, almost one-third of the length of the surangular in lateral view. The surangular fossa is deep. Anteriorly, the surangular is excluded in ventral view by the splenial and the dentary at approximately the same point as the mandibular symphysis (Figure 7E-7F).

Prearticular. The prearticular is only preserved on the right side. It is laterally compressed and elongate, positioned medial to the angular and lateral to the posteriormost splenial.

Dentition. The teeth are small and acutely pointed, with smooth, thin enamel lacking macroscopic ornamentation (Figure 8B). There is no pronounced constriction between the crown and root. The roots are not well-enough preserved to assess the presence or absence of apicobasal ridges, however, the root is smooth immediately basal to the crown. Crown height is $4 \mathrm{~mm}$ at the midpoint of the dentary. The teeth extend as far posteriorly as the anterior orbital margin.

Hyoid apparatus. The left ceratobranchial is preserved (Figure 7E-7F). An element in the position of the right hyoid is of questionable identity.

\section{Postcranial Axial Skeleton}

The atlas-axis complex is not visible. The third cervical centrum (C3) is the first vertebral centrum exposed on the right side. The right and left sides of the atlantal neural spine are unfused, and the atlantal neural spine is much smaller and shorter than the axial neural spine (Figure $8 \mathrm{C}$ ). The axial 
neural spine is twice as wide as that of C3 and more posterior dorsal neural spines, with an anterolateral facet for articulation with the atlantal spine (Figure 7D). Postzygapophyses appear to be paired until at least C7. Anterior dorsal centra bear paired apophyses. Vertebrae are taphonomically compressed.

The anteriormost dorsal ribs are bicapitate, but the tuberculum and capitulum are less clearly separated than in more posterior ribs (Figure 7B). Ribs bear an anterodorsal groove; this groove does not extend to the distal half of the rib. Some partial gastralia are preserved immediately posterior to the forelimb (Figure 7A).

\section{Pectoral Girdle}

Clavicle. The clavicle is wing-like, broadening medially and concave posteriorly with a thin dorsal process. It is twisted ventrally from the middle of the axis in such a way that the lateral ramus is offset approximately $120^{\circ}$ from the medial one (Figure $8 \mathrm{E})$. The medial ramus is more robust, broad, and convex than the lateral ramus. Whereas the medial ramus is slightly curved, the lateral one is flattened on both its dorsal and ventral surfaces.

Scapula. The anterior blade is concave in external view. An anterior expansion is present (Figure 8E). The coracoid facet is smaller than the glenoid facet. The posterior shaft of the scapula is dorsally straight and mediolaterally compressed. The posterior shaft is curved ventrally and slightly flared at its distal end. The ventral edge is proximodistally shorter than the dorsal edge.

Coracoid. The coracoid is saddle-shaped in external view, with the glenoid and scapular facets thickened and projecting ventrally. The coracoid is more or less equidimensional and rounded, and is almost as long as the median stem of the interclavicle (Figure 8E). An anterior notch is present but the posterior notch is reduced or absent. The glenoid facet is slightly rugose and much larger than the scapular facet. The intercoracoid facet is extremely reduced.

Interclavicle. The interclavicle is ' $T$ '-shaped. The posterior stem is approximately as long as the transverse bar. The transverse bar is relatively wide and convex in external view (Figure 8E). In anterior view, the transverse bar is broad and tapers laterally towards the tips.

\section{Forefin}

Humerus. The distal end of the humerus is wider than the proximal end, but not significantly so (Table 1; Figure 8D), and a mid-shaft constriction is present. The proximal anterior surface of the humerus is flattened. The dorsal process lies towards the anterior edge and is relatively small, extending less than half the length of the humeral shaft. In anterior view, it can be seen that the deltopectoral crest extends further distally than the dorsal process. The ulnar facet is longer than the radial facet. The anterior distal edge is slightly squared off, forming a prominent leading edge facet. The ulnar facet is straighter in dorsal view, whereas the radial facet is more concave.

Distal limb elements. The ulna and radius are in broad contact. The radius is notched anteriorly, and bears distal articular facets for the radiale and intermedium; the facet for the former is longer than that of the latter. The ulna is pentagonal in outline, with distal facets for the intermedium and ulnare. The pisiform is absent in FWD-129. The intermedium is pentagonal in outline, and forms a large contact with distal carpal 3 . The ulnare is very small and proximodistally short, smaller than the intermedium.

\section{Hauffiopteryx sp., Figure 9}

SMNS 81367, SMNS 80225, SMNS 81962, and SMNS 81965 are referable to Hauffiopteryx $\mathrm{sp}$., but the diagnostic portions of the skull are either not exposed or are damaged (Figure 9).

SMNS 81367 (Figure 9A) is a small individual with the skull preserved in dorsolateral and the postcranium preserved in ventrolateral views. The specimen is clearly referable to Hauffiopteryx based on the small, round supratemporal fenestrae, the palmate morphology of the supratemporal, and the location of the parietal foramen anterior to the anterior edge of the supratemporal fenestra. Extensive reconstruction in the narial region prevents an accurate assessment of morphology and thus specific referral. This specimen was figured as H. typicus by Pardo-Pérez et al. (2019).

SMNS 80225 (Figure 9B) is a poorly preserved specimen prepared in ventrolateral view. The skull has been partially reconstructed. This specimen is referred to Hauffiopteryx sp. based on the number and posterior extent of the gastralia. Fragmentary pelvic elements suggest the absence of a robust ischiopubis, also consistent with Hauffiopteryx. This specimen was considered to be referable to $H$. typicus by Maisch (2008).

SMNS 81962 (Figure 9C) is preserved in ventral view. The anterior rostrum has been reconstructed. This specimen is referred to Hauffiopteryx based on the reniform outline of the quadrate in lateral view, palmate supratemporal, and the hind limb with digits converging distally. 


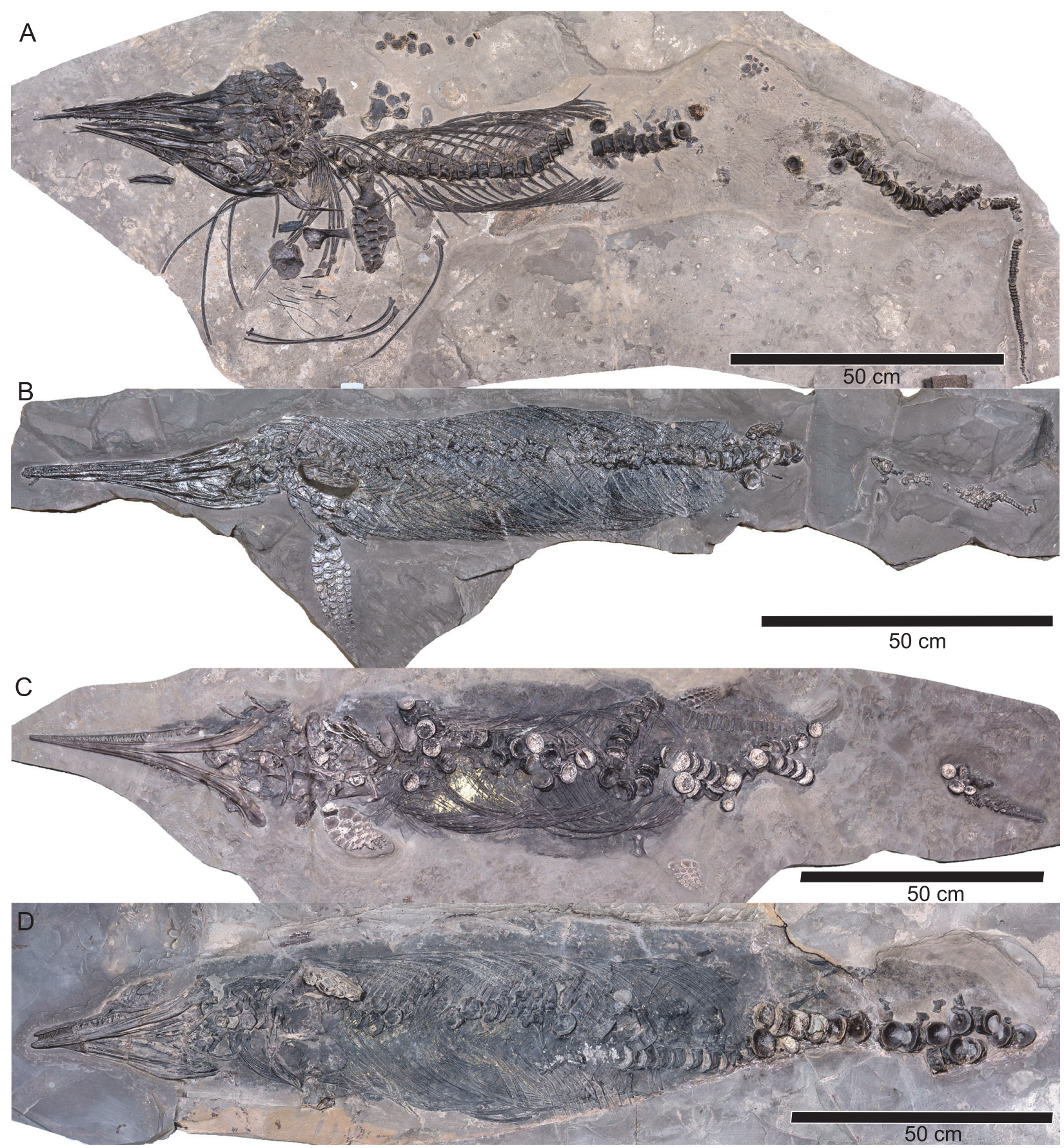

FIGURE 9. Hauffiopteryx sp. A, SMNS 81367; B, SMNS 80225; C, SMNS 81962; D, SMNS 81965. Photos @ SMNS / M. Wahler.

SMNS 81965 (Figure 9D) is also preserved in ventral view; the rostrum has been reconstructed. This specimen is considered to be referable to Hauffiopteryx based on the extensive development of gastralia, and the medially unfused ischium and pubis. An ossified hyoid corpus is present, a feature thusfar only observed in Hauffiopteryx among ichthyosaurs (Motani et al. 2013). SMNS 81965 was considered to be referable to $H$. typicus by Maisch (2008).

\section{PHYLOGENETIC ANALYSIS}

In order to test the relationship between material referred to Haffiopteryx typicus from the UK and Germany, Hauffiopteryx altera sp. nov., NMO 26575, and Leptonectes tenuirostris, we scored 
these as five separate OTUs in a version of the Moon (2017) Ichthyosauria matrix modified based on Maxwell et al. (2019). The Hauffiopteryx material from England was scored from the literature (Caine and Benton, 2011; Marek et al., 2015); NMO 26575 was scored based on personal observation (EM) and Maisch and Reisdorf (2006). In addition, we added the taxa Protoichthyosaurus prostaxalis and $P$. applebyi, scored based on Lomax et al. (2017, 2019a, 2019b) and Lomax and Massare (2018). Additional character and scoring changes are outlined in Appendices 2-3; the nexus file is provided in Appendix 4. We analyzed the data using maximum parsimony implemented in TNT v. 1.5 (Goloboff and Catalano, 2016) with a New Technology search (100 iterations of the ratchet algorithm, minimum length found 100 times) (Figure 10). Following parsimony analysis, the resulting MPTs were analyzed using the IterPCR script (Pol and Escapa, 2009), and 12 taxa causing instability were pruned from the strict consensus tree. Among neoichthyosaurian taxa, this resulted in Malawania anachronus, Temnodontosaurus eurycephalus, Pervushovisaurus bannovkensis, $P$. campylodon, and Simbirskiasaurus birjukovi being pruned (see Appendix 2 for complete list). A Bayesian analysis (Figure 11) was executed in Mr. Bayes. Search settings and taxon selection are outlined in Maxwell et al. (2019).

Both Bayesian and parsimony analyses support referral of NMO 26575 and FWD-129 to the genus Hauffiopteryx, distinct from all three species of Leptonectes (Figures 10-11). Moreover, material referred to Hauffiopteryx typicus from Germany and England formed a monophyletic group. We consider scoring differences between these $H$. typicus OTUs to be caused by differences in taphonomy (three-dimensional preservation vs. strong lateral compression), variation in the quality of preservation and preparation, and ontogeny, with the British material thought to represent juvenile individuals. Hauffiopteryx formed a sister group to Stenopterygius + Ophthalmosauridae in parsimony analysis (Figure 10); its position relative to Stenopterygius spp. and Leptonectes spp. was unresolved in Bayesian analysis (Figure 11).

\section{DISCUSSION}

\section{Comparison of Hauffiopteryx to Other Early Jurassic Ichthyosaurs}

Hauffiopteryx differs from all coeval Toarcian ichthyosaur genera in the extensive participation of the prefrontal in the external narial opening. The prefrontal is excluded in Temnodontosaurus trigonodon, Stenopterygius (Maisch, 1998a); Suevoleviathan (Maisch, 2001), Eurhinosaurus (SMNS 18648), as well as in Leptonectes (McGowan and Motani, 2003). The nasals in Hauffiopteryx are more extensively exposed dorsally anterior to the external narial opening than the premaxillae, unlike in Stenopterygius (e.g., Maxwell, 2012b). As in Eurhinosaurus (e.g., SMNS 18648), the upper temporal fenestrae are small and circular, the supratemporal is broad and palmate in morphology, and the parietal shelf is horizontally oriented. As in Temnodontosaurus trigonodon (Fraas, 1913), the splenial plays a major role in the mandibular symphysis. The teeth of Hauffiopteryx are slender and conical, with smooth enamel unlike in Suevoleviathan, in which the enamel is rugose in texture (Maxwell, 2018). In the postcranium, the gastralia in Hauffiopteryx extend posteriorly at least as far as the thirty-fifth vertebra. This is unique among Toarcian genera: gastralia are unknown in Temnodontosaurus trigonodon and Suevoleviathan; in Eurhinosaurus and Stenopterygius gastralia are present in the anterior- to mid-dorsal region (Buchholtz, 2001). The rib tuberculum and capitulum in the dorsal region are widely separated in Hauffiopteryx, as in Stenopterygius but unlike in Temnodontosaurus trigonodon, Eurhinosaurus, and Suevoleviathan (Maisch and Matzke, 2000). The anterior scapula is expanded and a foramen between the humerus, radius, and ulna is absent, unlike in Temnodontosaurus trigonodon (e.g., SMNS 17560). The elements of the anterior digit in both the fore- and hind limbs bear notches, and the proximal limb elements are angular and tightly interlocking, unlike in Suevoleviathan (Maisch, 1998b). The ischium and the pubis are thin and styloidal, unlike in Temnodontosaurus, Suevoleviathan, and Eurhinosaurus (Maisch and Matzke, 2000), but are widely separated medially, unlike in Stenopterygius in which they are fused both medially and laterally (Maisch and Matzke, 2000).

Parsimony analysis resolved the position of Hauffiopteryx as sister to Stenopterygius + Ophthalmosauridae (Figure 10). Although poor resolution outside this group increases ambiguity in character reconstruction, this clade is supported by a narrow, tapering anterior jugal, the basioccipital contributing to the floor of the foramen magnum in posterior view, a supraoccipital with parallel exoccipital processes, a caudal region approximately equal in length to the presacral vertebral column, one complete postaxial digit supported by an ulnare with two well-developed distal articular fac- 


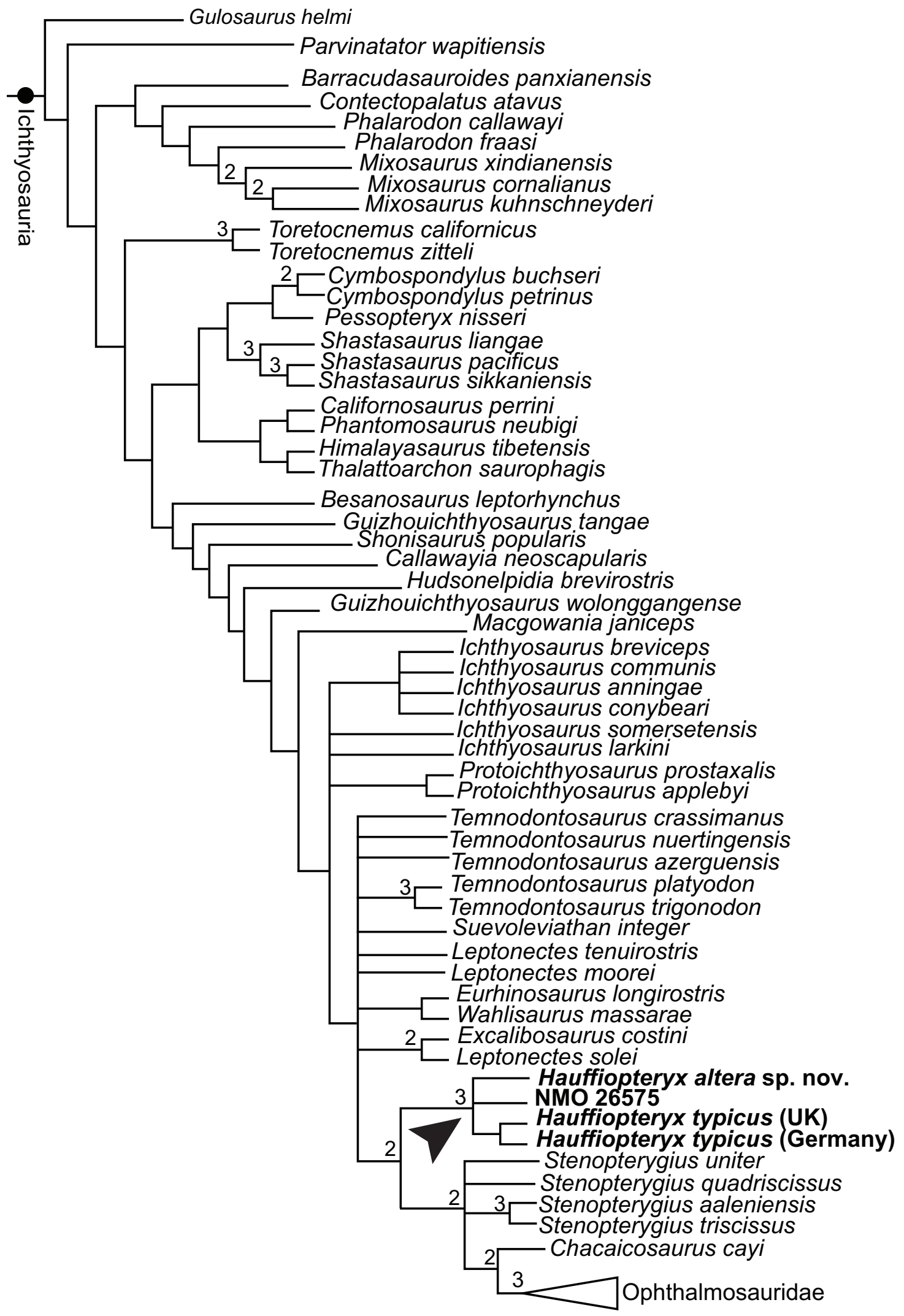

FIGURE 10. Strict consensus of 158 most parsimonious trees of length 1663; taxa flagged by IterPCR as being unstable have been pruned from the figure. The arrow indicates OTUs included in the genus Hauffiopteryx. Bremer support values greater than 1 are indicated to the left of the nodes. 


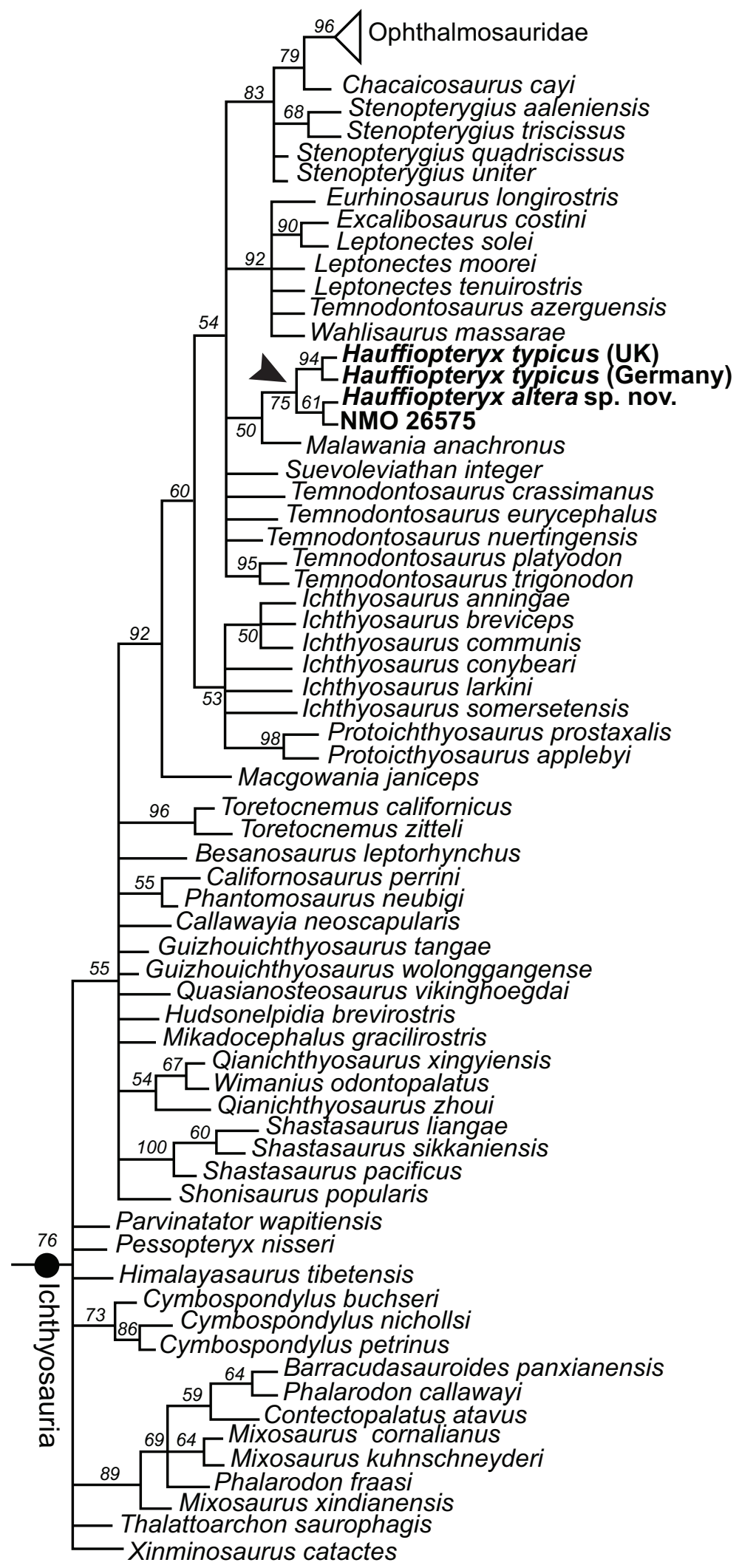

FIGURE 11. 50\% majority rule tree derived from Bayesian analysis. Clade credibility values indicated to the left of the nodes. The arrow indicates OTUs included in the genus Hauffiopteryx. 
TABLE 2. Hauffiopteryx comparative measurements (mm).

\begin{tabular}{|c|c|c|c|c|c|}
\hline Specimen/taxon & $\begin{array}{c}\text { Approximate } \\
\text { presacral length } \\
\text { (without skull) }\end{array}$ & $\begin{array}{l}\text { Lower jaw } \\
\text { (length) }\end{array}$ & $\begin{array}{c}\text { Antorbital } \\
\text { rostrum }\end{array}$ & $\begin{array}{c}\text { Humerus } \\
\text { (length) }\end{array}$ & $\begin{array}{l}\text { Femur } \\
\text { (length) }\end{array}$ \\
\hline FWD-129 (H. altera sp. nov.) & -- & $>280$ & -- & 46 & -- \\
\hline GPIT 1491/4 (H. typicus) & 620 & 380 & $\sim 216$ & 57 & 35 \\
\hline GPIT/RE/12905 (H. typicus) & -- & 462 & 306 & -- & -- \\
\hline BRSLI M1399 (H. typicus) & $590^{*}$ & 322 & $192^{*}$ & $47^{*}$ & $30^{*}$ \\
\hline SMNS 51552 (H. typicus) & $\sim 930$ & $>520$ & $>295$ & 75 & 54 \\
\hline SMNS 80226 (H. typicus) & $\sim 879$ & 440 & 258 & 59 & 40 \\
\hline MHH 9 (H. typicus) & -- & 460 & 282 & $68^{* *}$ & -- \\
\hline NMO 26575 (H. typicus) & -- & $370-400 \mathrm{~mm}^{\star \star *}$ & $247^{\star * *}$ & -- & -- \\
\hline SMNS 81367 (Hauffiopteryx sp.) & -- & 385 & -- & 60 & -- \\
\hline SMNS 80225 (Hauffiopteryx sp.) & $\sim 809$ & incomplete & incomplete & 53 & 30 \\
\hline SMNS 81962 (Hauffiopteryx sp.) & -- & -- & -- & -- & 49 \\
\hline SMNS 81965 (Hauffiopteryx sp.) & $\sim 997$ & $>280$ & -- & 57 & -- \\
\hline
\end{tabular}

ets, polygonal metacarpals and phalanges, and lateral fusion of the ischiopubis. The strongly grooved ribs with broadly separated tuberculum and capitulum in the mid-dorsal region are also different from all leptonectids (Maisch and Matzke, 2000).

In the skull, greater similarities to leptonectids are present - especially in the dermatocranium. These include the thin rostrum with elongated external narial opening, the small upper temporal fenestra, the enlarged, palmate supratemporal, the horizontally oriented parietal slope, and the slight overbite. However, unexpected similarities with Temnodontosaurus (e.g., SMNS 50000) are also identified in the skull: the anteroposterior orientation and large size of the extracondylar area (ECA) of the basioccipital rather than the ECA being dorsoventrally oriented, such as that of Eurhinosaurus (SMNS 18648) and to a lesser extent Leptonectes tenuirostris and Wahlisaurus (Lomax and Massare, 2012; Lomax, 2016), and the extensive participation of the splenial in the mandibular symphysis (see Fraas, 1913). These differences support an independent derivation of a longirostrine morphotype in Leptonectidae and Hauffiopteryx, as argued by Moon (2017), although unlike Moon we recover $T$. azerguensis as a leptonectid in the Bayesian analysis (Figure 11).

Maisch (2008) was of the opinion that Hauffiopteryx typicus was characterized by certain unusual ontogenetic changes, namely: 1) strong positive allometry of the antorbital rostrum relative to the skull with increasing body size, and 2) strong positive allometry of the skull relative to presacral length. Unfortunately, the rostrum appears to have been reconstructed/modified in most of the available specimens of $H$. typicus, with the exception of GPIT 1491/4, GPIT/RE/12905, SMNS 80226, MHH 9, and BRSLI M1399 (see Table 2 for raw measurements). Based on log-transformed data, the antorbital rostrum appears to have grown with weak positive allometry relative to the lower jaw (slope =1.15), and the lower jaw grew with strong negative allometry relative to the presacral vertebral column, the humerus, and to a lesser extent, the femur (as reported for e.g., Stenopterygius quadriscissus and Ichthyosaurus communis: McGowan, 1973). Thus, at present there is some support for the view that antorbital rostrum of Hauffiopteryx typicus showed a different allometric growth pattern than Ichthyosaurus and Stenopterygius, although there is enough variation present that this pattern is not clearly apparent in the ratios of individual specimens.

\section{Ontogenetic Status of FWD-129 and Generic Referral of Hauffiopteryx altera}

FWD-129 shows multiple features consistent with Hauffiopteryx from both the Posidonienschiefer Formation as well as from coeval localities in England, but differs from Stenopterygius, the most abundant and widespread ichthyosaur genus during the Toarcian. Characters supporting the referral of FWD-129 to Hauffiopteryx include participation of the prefrontal in the posterior external 
narial opening, small, round upper temporal fenestrae situated posterior to the pineal foramen, short nasals that do not contact the parietals, and a forefin with tightly interlocking, polygonal phalanges with a notch on the elements of the leading edge digit (Maisch, 2008; Caine and Benton, 2011). This combination of features is consistent with Hauffiopteryx among all ichthyosaurian genera, and this referral is also supported by both parsimony and Bayesian phylogenetic analysis (Figures 10-11). However, FWD-129 differs from $H$. typicus based on some aspects of cranial anatomy.

Maisch (2008) considered individuals of Hauffiopteryx typicus of less than $2.5 \mathrm{~m}$ total length to be juveniles. Thus, using Maisch's criterion, with a total length of $193 \mathrm{~cm}$ (Table 2) GPIT 1491/4 would be a juvenile; however, we suspect that the specimen is osteologically mature based on the convex shape of the proximal humerus and closure of the sutures between phalanges (Johnson, 1977). Caine and Benton (2011) estimated total length in BRLSI M1399 at $150 \mathrm{~cm}$ (skull length = $322 \mathrm{~mm}$; humerus $=47 \mathrm{~mm}$ [from photo: Caine and Benton, 2011: text-fig. 9]); this specimen has been generally interpreted as a juvenile (Caine and Benton, 2011; Marek et al., 2015).

FWD-129 was initially considered to be a juvenile of Eurhinosaurus longirostris, due to its small size, large orbits, and small temporal fenestra (Jäger, 2005). FWD-129 is approximately equal in size to BRLSI M1399, with a lower jaw at least $280 \mathrm{~mm}$ in length and a humerus $46 \mathrm{~mm}$ in length (Table 2). The proximal articular surface of the humerus is flat, and the sutures between the limb elements remain open, also strongly supporting a juvenile attribution for this specimen. Relative proportions of the skull to the postcranium (McGowan, 1973), proportions within the skull (especially pertaining to the orbit/sclerotic ring: Fernández et al., 2005), relative tooth size (Dick and Maxwell, 2015), and notching of the anterior limb elements (Maxwell et al., 2014) are known to be ontogenetically influenced in the closely related genus Stenopterygius. However, the characteristics separating FWD-129 from specimens referred to $H$. typicus, Stenopterygius, and Eurhinosaurus are not expected to vary ontogenetically. This is especially apparent given that FWD-129 is of a similar ontogenetic stage to BRLSI M1399 based on both absolute size and limb ossification, but shows numerous differences in cranial morphology.

\section{Comparison of Hauffiopteryx altera with Hauffiopteryx typicus}

The lectotype of $H$. typicus (GPIT 1491/4) from Holzmaden is severely crushed, whereas FWD-129 is a lightly compressed three-dimensional skeleton. Nevertheless, it is possible to identify ways in which the two skulls differ. In H. typicus, the orbit is very large and round, creating a steep inflection in the nasal in lateral view. In FWD-129, the orbit is more elongate, and in lateral view the nasals are less steeply inflected anterior to the orbit than in H. typicus. SMNS 51552 and $\mathrm{MHH} 9$ (Figure 2B, 2C) are much more similar in shape to the lectotype of $H$. typicus (GPIT 1491/4; Figure 2A) than to FWD-129 (Figure 7C). Unlike in GPIT 1491/4, MHH 9, and SMNS 51552, the lacrimal of FWD-129 does not separate the prefrontal from the jugal, and is excluded from the external narial opening. The lacrimal of FWD-129 is more robust than in specimens referred to $H$. typicus. These differences result in a relatively larger distance between the anterior edge of the orbit and the narial opening in FWD-129 than in $H$. typicus. The maxilla is overlapped dorsally by the lacrimal over almost one third of the posterodorsal surface, and the maxilla forms the ventral edge of much of the external nares in the lectotype, $\mathrm{MHH}$ 9, and SMNS 51552. In FWD-129, it is the jugal rather than the lacrimal that overlaps the maxilla posteriorly, and the maxilla is almost entirely excluded from the external narial opening in lateral view.

BRLSI M1399 has a shallower, more elongated maxilla than FWD-129, but the maxilla of FWD-129 has a greater contact with the ventral surface of the premaxilla than that of BRLSI M 1399 , with the premaxilla extending well past the midpoint of the external nares in the former specimen. The maxilla of FWD-129 is slightly deeper posteriorly, whereas in the English specimen the maxilla is rather similar in depth along its entire length. The maxilla of FWD-129 contacts the lacrimal and prefrontal posterodorsally, whereas in BRLSI M1399 the maxilla contacts only the lacrimal. The lacrimal of BRLSI M1399 participates posteriorly in the external narial opening (Marek et al., 2015: fig. 1; Caine and Benton, 2011: fig. 9); however, in FWD-129 it is excluded from the external narial opening by the prefrontal. In dorsal view, the prefrontal in FWD-129 is anteroventrally narrower than that of BRLSI M1399. Also, the narial ramus is more anteroposteriorly oblique in relation to the oval orbit. The jugal extends much further anteriorly in FWD-129 than in BRLSI M1399 (Caine and Benton, 2011: fig. 12; Marek et al., 


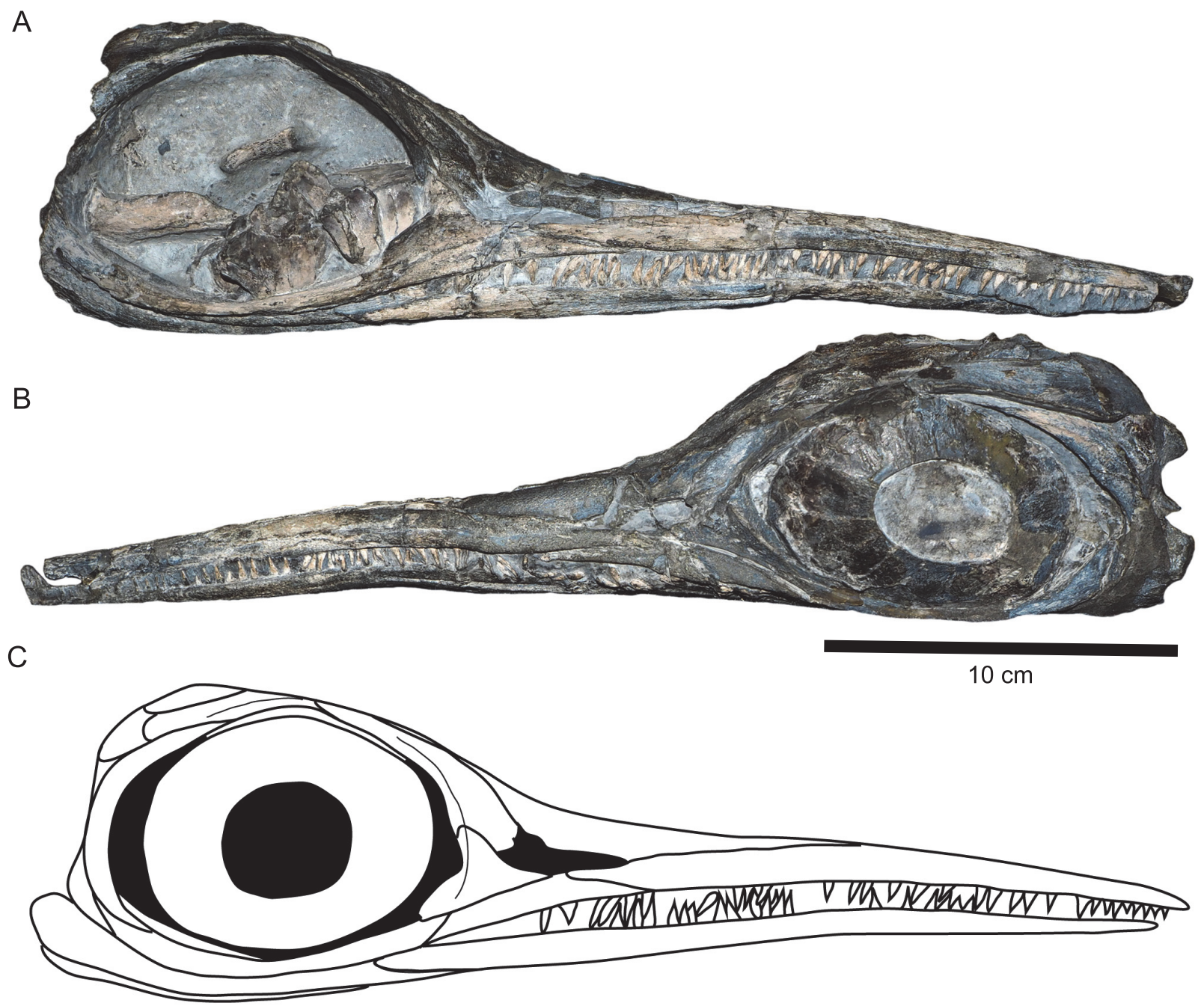

FIGURE 12. Hauffiopteryx typicus, NMO 26575. Skull in (A) right and (B) left lateral view; 3, reconstruction, redrawn from Maisch and Reisdorf (2006).

2015: fig. 1). The orbit is also rounder in BRLSI M1399. These features are very similar to the set of characters differentiating FWD-129 from $\mathrm{H}$. typicus, consistent with our interpretation of BRLSI M1399 as referable to $H$. typicus.

Marek et al. (2015) cited the absence of root striations, the absence of the narial process of the maxilla, the presence of the temporal process of the frontal, wing-like basipterygoid processes, the absence of a ventral notch in the extracondylar area of the basioccipital, and the rod-like ischium/ ischiopubis as differing between Hauffiopteryx and BRLSI M1399. However, some of these conclusions are the result of character scoring errors: BRLSI M1399 has a ventral notch in the extracondylar area of the basioccipital (Marek et al., 2015: fig. 10a), and lacks participation of the frontal in the supratemporal fenestra (i.e., processus temporalis of the frontal absent, Marek et al., 2015: fig. 4a). The only character listed that truly differs between $H$. typicus and BRLSI M1399 is the absence of root striations in the latter; however, Marek et al. (2015) state that the teeth are quite poorly preserved, which may affect character scoring. For that reason, we consider BRLSI M1399 to be referable to H. typicus. Hauffiopteryx typicus from England and Germany formed a monophyletic group in our analyses, to the exclusion of NMO 26575 and Hauffiopteryx altera sp. nov. (Figures 9-10).

\section{Comparison of Hauffiopteryx typicus to NMO 26575}

Maisch and Reisdorf (2006) referred a small ichthyosaur from the late Pliensbachian of Switzerland to the much older Rhaetian-Sinemurian species Leptonectes tenuirostris (Figure 12). However, 
this specimen shares greater similarity with the stratigraphically less far-removed genus Hauffiopteryx than with Leptonectes tenuirostris based on its small size, cranial proportions, significant participation of the prefrontal in the posterodorsal edge of the external nares, and angular, closely packed limb elements with multiple notches along the anterior digit of the forelimb. NMO 26575 is distinct from Hauffiopteryx altera in that the jugal is quite short, and the prefrontal does not exclude the lacrimal from the posterior edge of the external nares. NMO 26575 is more similar to $H$. typicus in this and most respects, and we consider it to be referable to $H$. typicus, resulting in a range extension of at least 2 million years for both the genus and the species. One of the key differences between most skulls referred to $H$. typicus and NMO 26575 is the proximity between the anterior lacrimal and subnarial process of the premaxilla in the latter, excluding the maxilla from participation in the external narial opening. However, the morphology observed in GPIT/RE/12905, in which the anterior lacrimal contacts the subnarial process of the premaxilla to exclude the maxilla from the narial opening, suggests that the anterior process of the lacrimal is variable in length in $H$. typicus and that $\mathrm{NMO}$ 26575 is within the range of variation of this species. Instraspecific variation in this part of the skull has already been noted in other Early Jurassic ichthyosaurs: e.g., in Protoichthyosaurus prostaxalis (Lomax et al., 2019a), and Stenopterygius triscissus (compare Godefroit, 1994: fig. 19; Caine and Benton, 2011: text-fig. 3).

\section{Palaeoecology}

The palaeoecology of the morphologically similar genus Stenopterygius is relatively well understood, and includes dietary information for individuals over a wide range of body sizes (Dick et al., 2016), complete ontogenetic series (von Huene, 1922), and embryonic material (Böttcher, 1990). In contrast, Hauffiopteryx is much less abundant. The material listed in the current contribution represents the complete sample of Hauffiopteryx known from publicly accessible collections. Preserved individuals fall into a much narrower size range than Stenopterygius (Table 2 vs. Maxwell, 2012b supplementary table 1) and embryos are unknown, limiting our understanding of ontogenetic variation in this genus. Recognizable prey items are lacking as gastric contents. Thus, how Hauffiopteryx may functionally differ from Stenopterygius is extremely speculative.
Although referral of NMO 26575 to Hauffiopteryx typicus extends the stratigraphic range of the genus and species into the upper Pliensbachian, all finds from the Posidonienschiefer Formation are concentrated in a very narrow stratigraphic range, from the uppermost tenuicostatum Zone to the lowermost serpentinum Zone. This time period corresponds to the onset to the peak of the early Toarcian Oceanic Anoxic Event, an event that profoundly influenced composition and abundance of both vertebrate and invertebrate faunas in the southwest German Basin (e.g., Hauff, 1921; Maxwell and Vincent, 2016). It is thus possible that Hauffiopteryx had a particularly specialized diet or hunting strategy, and its sudden reappearance in and subsequent disappearance from - the basin was related to changes in prey abundance or habitat (e.g., bottom-water anoxia forcing fish and belemnites into a narrow zone near the sea surface: Ullmann et al., 2014).

\section{CONCLUSIONS}

We found no evidence that the English and German material referred to the genus Hauffiopteryx represent separate species; however, we do find evidence that two species of Hauffiopteryx were present in the Early Jurassic of the Southwest German Basin: $H$. typicus and $H$. altera sp. nov. These two taxa are differentiated primarily based on characters pertaining to the lacrimal, prefrontal, and jugal. In addition, we refer a specimen previously considered to be Leptonectes tenuirostris to Hauffiopteryx typicus, extending the range of the genus into the Pliensbachian. This result is supported by phylogenetic analysis, which recovers Hauffiopteryx as a sister group to Stenopterygius + Ophthalmosauridae. Hauffiopteryx represents a valid genus, defined by a suite of synapomorphies involving both the skull and postcranium. However, the functional and paleoecological significance of these characters differentiating Hauffiopteryx from the superficially similar genus Stenopterygius are unclear.

\section{ACKNOWLEDGEMENTS}

We would like to thank A. Schmid-Röhl (FWD), I. Werneburg (GPIT), R. Hauff (MHH), and D. Steinmann (NMO) for collections access, and C. Gascó Martín for partial preparation of SMNS 80226. DC thanks C. Jaramillo (STRI), the Smithsonian Tropical Research Institute, the Anders Foundation, the 1923 Fund, G.D. and J.W. Johnson, an NSERC CREATE 466283-2015, and an 
NSERC Discovery Grant to H. Larsson (McGill University, Canada), for funding and support, and $\mathrm{J}$. Pardo-Pérez (SMNS, U. Magallanes, Chile) and C. Gascó Martín (SMNS) for discussion and logistical support. The suggestions of A. Wolniewicz, N. Zverkov, and an anonymous reviewer improved the manuscript.

\section{REFERENCES}

Böttcher, R. 1989. Über die Nahrung eines Leptopterygius (Ichthyosauria, Reptilia) aus dem süddeutschen Posidonienschiefer (Unterer Jura) mit Bemerkungen über den Magen der Ichthyosaurier. Stuttgarter Beiträge zur Naturkunde Serie B (Geologie und Paläontologie), 155:1-19.

Böttcher, R. 1990. Neue Erkenntnisse über die Fortpflanzungsbiologie der Ichthyosaurier (Reptilia). Stuttgarter Beiträge zur Naturkunde Serie B (Geologie und Paläontologie), 164:1351.

Buchholtz, E.A. 2001. Swimming styles in Jurassic ichthyosaurs. Journal of Vertebrate Paleontology, 21:61-73.

Caine, H. and Benton, M.J. 2011. Ichthyosauria from the Upper Lias of Strawberry Bank, England. Palaeontology, 54:1069-1093. https://doi.org/10.1111/j.1475-4983.2011.01093.x

de Blainville, H.M.D. 1835. Description de quelques espèces de reptiles de la Californie: précédée de l'analyse d'un système général d'erpétologie et d'amphibiologie. Nouvelles Annales du Muséum d'Histoire Naturelle, Paris, 4:233-296.

Dick, D.G. and Maxwell, E.E. 2015. Ontogenetic tooth reduction in Stenopterygius quadriscissus (Reptilia: Ichthyosauria): negative allometry, changes in growth rate, and early senescence of the dental lamina. PloS ONE, 10:e0141904. https://doi.org/10.1371/journal.pone.0141904

Dick, D.G., Schweigert, G., and Maxwell, E.E. 2016. Trophic niche ontogeny and palaeoecology of Early Toarcian Stenopterygius (Reptilia: Ichthyosauria). Palaeontology, 59:423-431. https:/ /doi.org/10.1111/pala.12232

Fernández, M.S., Archuby, F., Talevi, M., and Ebner, R. 2005. Ichthyosaurian eyes: paleobiological information content in the sclerotic ring of Caypullisaurus (Ichthyosauria, Ophthalmosauria). Journal of Vertebrate Paleontology, 25:330-337. https://doi.org/10.1671/ 0272-4634(2005)025[0330:IEPICI]2.0.CO;2

Fischer, V., Bardet, N., Benson, R.B., Arkhangelsky, M.S., and Friedman, M. 2016. Extinction of fish-shaped marine reptiles associated with reduced evolutionary rates and global environmental volatility. Nature Communications, 7:10825. https://doi.org/10.1038/ ncomms 10825

Fraas, E. 1913. Einunverdrückter Ichthyosaurus-Schädel. Mitteilungen aus dem K. Naturalienkabinett, 79:1-12.

Godefroit, P. 1994. Les reptiles marins du Toarcien (Jurassique inferieur) belgo-luxembourgeois. Mémoires pour servir à l'Explication des Cartes Géologiques et Minières de la Belgique, 39:1-98.

Goloboff, P. and Catalano, S. 2016. TNT, version 1.5, with a full implementation of phylogenetic morphometrics. Cladistics, 32(3):221-238. https://doi.org/10.1111/cla.12160

Hänggi, H. and Reisdorf, A. 2007. Der Ichthyosaurier vom Hauensteiner Nebelmeer. Naturforschende Gesellschaft des Kantons Solothurn Mitteilungen, 2007:7-22.

Hauff, B. 1921. Untersuchung der Fossilfundstätten von Holzmaden im Posidonienschiefer des Oberen Lias Württembergs. Palaeontographica, 64:1-42.

Goloboff, P.A., Farris, J.S., and Nixon, K.C. 2008. TNT, a free program for phylogenetic analysis. Cladistics, 24:774-786. https://doi.org/10.1111/j.1096-0031.2008.00217.x

Huelsenbeck, J. P. and Ronquist, F. 2001. MRBAYES: Bayesian inference of phylogenetic trees. Bioinformatics, 17:754-755.

Jäger, M. 2005. The Museum of Fossils in the Werkforum: Guidebook of the Exhibition of Jurassic Fossils (third edition). Holcim, Dotternhausen, Germany.

Ji, C., Jiang, D.-Y., Motani, R., Rieppel, O., Hao, W.-C., and Sun, Z.-Y. 2016. Phylogeny of the Ichthyopterygia incorporating recent discoveries from South China. Journal of Vertebrate Paleontology, 36:e1025956. https://doi.org/10.1080/02724634.2015.1025956 
Johnson, R. 1977. Size independent criteria for estimating relative age and the relationships among growth parameters in a group of fossil reptiles (Reptilia: Ichthyosauria). Canadian Journal of Earth Sciences, 14:1916-1924.

Lomax, D.R. 2016. A new leptonectid ichthyosaur from the Lower Jurassic (Hettangian) of Nottinghamshire, England, UK, and the taxonomic usefulness of the ichthyosaurian coracoid. Journal of Systematic Palaeontology, 15:387-401. https://doi.org/10.1080/ 14772019.2016.1183149

Lomax, D.R. and Massare, J.A. 2012. The first reported Leptonectes (Reptilia: Ichthyosauria) with associated embryos, from Somerset, England. Paludicola, 8:263-276.

Lomax, D.R. and Massare, J.A. 2018. A second specimen of Protoichthyosaurus applebyi (Reptilia: Ichthyosauria) and additional information on the genus and species. Paludicola, 11:164-178.

Lomax, D.R., Massare, J.A., and Evans, M. 2019a. New information on the skull roof of Protoichthyosaurus (Reptilia: Ichthyosauria) and intraspecific variation in some dermal skull elements. Geological Magazine, 157:640-650. https://doi.org/10.1017/S0016756819001225

Lomax, D.R., Massare, J.A., and Mistry, R.T. 2017. The taxonomic utility of forefin morphology in Lower Jurassic ichthyosaurs: Protoichthyosaurus and Ichthyosaurus. Journal of Vertebrate Paleontology, 37:e1361433. https://doi.org/10.1080/02724634.2017.1361433

Lomax, D.R., Porro, L.B., and Larkin, N.R. 2019b. Descriptive anatomy of the largest known specimen of Protoichthyosaurus prostaxalis (Reptilia: Ichthyosauria) including computed tomography and digital reconstruction of a three-dimensional skull. PeerJ 7: e6112. https:// doi.org/10.7717/peerj.6112

Maisch, M.W. 1998a. Kurze Übersicht der Ichthyosaurier des Posidonienschiefers mit Bemerkungen zur Taxonomie der Stenopterygiidae und Temnodontosauridae. Neues Jahrbuch für Geologie und Paläontologie Abhandlungen, 209:401-431.

Maisch, M.W. 1998b. A new ichthyosaur genus from the Posidonia Shale (Lower Toarcian, Jurassic) of Holzmaden, SW-Germany with comments on the phylogeny of post-Triassic ichthyosaurs. Neues Jahrbuch für Geologie und Paläontologie Abhandlungen, 209(1):47-78.

Maisch, M.W. 2001. Neue Exemplare der seltenen Ichthyosauriergattung Suevoleviathan Maisch 1998 aus dem Unteren Jura von Südwestdeutschland. Geologica et Palaeontologica, 35:145-160.

Maisch, M.W. 2008. Revision der Gattung Stenopterygius Jaekel, 1904 emend. von Huene, 1922 (Reptilia: Ichthyosauria) aus dem Unteren Jura Westeuropas. Paleodiversity, 1:227271.

Maisch, M.W. and Matzke, A.T. 2000. The Ichthyosauria. Stuttgarter Beiträge zur Naturkunde Serie B (Geologie und Paläontologie), 298:1-159.

Maisch, M.W. and Reisdorf, A.G. 2006. Evidence for the longest stratigraphic range of a postTriassic ichthyosaur: a Leptonectes tenuirostris from the Pliensbachian (Lower Jurassic) of Switzerland. Geobios, 39:491-505. https://doi.org/10.1016/j.geobios.2005.04.005

Marek, R.D., Moon, B.C., Williams, M., and Benton, M.J. 2015. The skull and endocranium of a Lower Jurassic ichthyosaur based on digital reconstructions. Palaeontology, 58:723-742. https://doi.org/10.1111/pala.12174

Maxwell, E.E. 2012a. Unraveling the influences of soft-tissue flipper development on skeletal variation using an extinct taxon. Journal of Experimental Zoology Part B: Molecular and Developmental Evolution, 318:545-554. https://doi.org/10.1002/jez.b.22459

Maxwell, E.E. 2012b. New metrics to differentiate species of Stenopterygius (Reptilia: Ichthyosauria) from the Lower Jurassic of southwestern Germany. Journal of Paleontology, 86:105-115.

Maxwell, E.E. 2018. Redescription of the 'lost' holotype of Suevoleviathan integer (Bronn, 1844) (Reptilia: Ichthyosauria). Journal of Vertebrate Paleontology, 38(2):e1439833. https://doi.org/ 10.1080/02724634.2018.1439833

Maxwell, E.E., Cortés, D., Patarroyo, P., and Parra Ruge, M.L. 2019. A new specimen of Platypterygius sachicarum (Reptilia: Ichthyosauria) from the Early Cretaceous of Colombia and its phylogenetic implications. Journal of Vertebrate Paleontology, 39: e1577875. https:// doi.org/10.1080/02724634.2019.1577875

Maxwell, E.E., Scheyer, T.M., and Fowler, D.A. 2014. An evolutionary and developmental perspective on the loss of regionalization in the limbs of derived ichthyosaurs. Geological Magazine, 151:29-40. https://doi.org/10.1017/S0016756812001070 
Maxwell, E.E. and Vincent, P. 2016. Effects of the early Toarcian Oceanic Anoxic Event on ichthyosaur body size and faunal composition in the Southwest German Basin. Paleobiology, 42:117-126. https://doi.org/10.1017/pab.2015.34

McGowan, C. 1973. Differential growth in three ichthyosaurs: Ichthyosaurus communis, I. breviceps, and Stenopterygius quadriscissus (Reptilia, Ichthyosauria). Life Sciences Contributions, Royal Ontario Museum, 93:1-21.

McGowan, C. 1978. Further evidence for the wide geographical distribution of ichthyosaur taxa (Reptilia: Ichthyosauria). Journal of Paleontology, 52:1155-1162.

McGowan, C. 1992. Unusual extensions of the neural spines in two ichthyosaurs from the Lower Jurassic of Holzmaden. Canadian Journal of Earth Sciences, 29:380-383.

McGowan, C. and Motani, R. 2003. Ichthyopterygia. Verlag Dr. Friedrich Pfeil, München.

Moon, B.C. 2017. A new phylogeny of ichthyosaurs (Reptilia: Diapsida). Journal of Systematic Palaeontology, 17:129-155. https://doi.org/10.1080/14772019.2017.1394922

Motani, R. 1999. Phylogeny of the Ichthyopterygia. Journal of Vertebrate Paleontology, 19:473496.

Motani, R., Ji, C., Tomita, T., Kelley, N., Maxwell, E., Jiang, D., and Sander, P.M. 2013. Absence of suction feeding ichthyosaurs and its implications for Triassic mesopelagic paleoecology. PloS ONE, 8:e66075. https://doi.org/10.1371/journal.pone.0066075

Owen, R. 1859. On the orders of fossil and recent Reptilia, and their distribution in time. Report for the British Association for the Advancement of Science, Aberdeen, 1859:153-166.

Pardo-Pérez, J., Kear, B.P., and Maxwell, E.E. 2019. Palaeoepidemiology in extinct vertebrate populations: factors influencing skeletal health in Jurassic marine reptiles. Royal Society Open Science, 6:190264. https://doi.org/10.1098/rsos.190264

Pol, D. and Escapa, I.H. 2009. Unstable taxa in cladistic analysis: identification and the assessment of relevant characters. Cladistics, 25:515-527. https://doi.org/10.1111/j.10960031.2009.00258.x

Ronquist, F. and Huelsenbeck, J.P. 2003. MrBayes 3: Bayesian phylogenetic inference under mixed models. Bioinformatics, 19:1572-1574. https://doi.org/10.1093/bioinformatics/btg180

Theodori, C. 1843. Über einen kolossalen Ichthyosaurus trigonodon. Gelehrte Anzeigen der königlich bayerischen Akademie der Wissenschaften, 16:906-911.

Ullmann, C.V., Thibault, N., Ruhl, M., Hesselbo, S.P., and Korte, C. 2014. Effect of a Jurassic oceanic anoxic event on belemnite ecology and evolution. Proceedings of the National Academy of Sciences, 111:10073-10076. https://doi.org/10.1073/pnas.1320156111

Urlichs, M., Wild, R., and Ziegler, B. 1994. Der Posidonien-Schiefer und seine Fossilien. Stuttgarter Beiträge zur Naturkunde C, 36:1-95.

von Huene, F.R. 1922. Die Ichthyosaurier des Lias und ihre Zusammenhänge. Gebrüder Borntraeger, Berlin.

von Huene, F.R. 1931. Neue Studien über Ichthyosaurier aus Holzmaden. Abhandlungen der Senckenbergischen Naturforschenden Gesellschaft, 42:345-382. 


\section{APPENDIX 1.}

Selected measurements of specimens examined during this study (.xls). (Available in zipped file at https://palaeo-electronica.org/content/2020/3078-revision-of-hauffiopteryx.)

\section{APPENDIX 2.}

Discussion of character and taxon scoring changes from past analyses.

Our phylogenetic analysis was based on the matrix developed by Moon (2017) and modified by Maxwell et al. (2019). In addition to rescoring Hauffiopteryx, we made the following revisions to characters and scoring:

Character 50: The position of the parietal foramen is more complex than initially captured in this character. We divided state (1) into two separate states. Rescoring affected only Ichthyosaurus.

Character 50 Parietals - location of the parietal foramen: (0) contact between the left and right parietals present anteriorly, frontal excluded from the parietal foramen; (1) on the frontoparietal suture; (2) entirely surrounded by the frontals (modified from Motani 1999c, character 19).

Character 89: The transverse flange of the pterygoid (character 88) is absent in most ichthyosaurs (Maisch and Matzke, 2000), which are scored as "poorly developed" in the matrix of Moon (2017: character 88). We therefore rescore character 89 as '-' in these cases.

Characters 165, 166: In the analysis of Moon (2017), characters 165-166 are duplicated as currently organized (i.e. a sacrum is present by definition only if differentiated sacral ribs are present). Moreover, no taxa in the sample have a sacrum as defined by character 165 (ribs sutured to ilium). For that reason, we restructure characters $165-166$ as follows:

Character 165: Sacrum (0) present (at least one morphologically differentiated sacral rib can be observed), (1) absent (no truly sacral ribs are present)(Motani, 1999 character 104 [part]).

Character 166: Sacral ribs (0) two with distal expansion, (1) one with distal expansion, (2) present and morphologically distinct [see character 165] but no distal expansion present. This character is treated as ordered.

Character 210: As scored by Moon (2017), this character is uninformative. This character was rescored based on pers. observ. of specimens at the SMNS and from the NHMUK digital collections interface, and such a notch separating the radial and ulnar facets of the distal humerus was observed in $T$. trigonodon, $T$. platyodon, and $S$. integer. Because such a notch may exist even in the presence of a humerus-intermedium contact, character 210 was scored for all taxa.

Character 221: A small interosseous foramen is present between the radius and ulna in $T$. trigonodon, T. platyodon (see McGowan, 1979), and Suevoleviathan. This character was rescored accordingly.

Character 240: In basal ichthyopterygians, metacarpal $\mathrm{V}$ is much larger than distal carpal IV, whereas in more derived forms these elements are subequal or metacarpal $\mathrm{V}$ may be lost entirely (Maisch and Matzke 2000b, character 100). In the character list Moon (2017), the character states were incorrectly transcribed. We have edited this error; the character-taxon matrix was not affected. Mixosaurus kuhnschneyderi: Rescored for character 118.

Guizhouichthyosaurus wolonggangense: The following characters were rescored based on reinterpretation of forelimb homologies in the original description, in which digit I is absent (and therefore metacarpal $\mathrm{V}$ is present): 217, 219, 229, 233, 236, 237, 240, 243, 247, 248. Characters 35-45 were also rescored based on the description of the type specimen.

Guizhouichthyosaurus tangae: character 35, 41, 229 rescored based on type description.

Callawayia neoscapularis: characters 35, 43, 229 rescored.

Ichthyosaurus communis and I. larkini: Scoring corrected for Characters 42 and 43 (temporal process of the frontal absent).

Protoichthyosaurus prostaxalis and Protoichthyosaurus applebyi were scored based on Lomax and Massare, 2018; Lomax et al., 2017, 2019a,b.

Temnodontosaurus trigonodon: Rescored for character 219 , since a postaxial manual accessory digit is absent.

Temnodontosaurus crassimanus was rescored for characters 47-48, 54, 73, 204, 207, 209, 214, 219, 226, 230, 240, 243 based on Melmore (1930). Additionally, we assume that Melmore (1930) misinterpreted the anterior-posterior polarity of the 
hind limb. This results in rescoring of characters 273 and 284.

Temnodontosaurus azerguensis was rescored for characters 227, 229, and 250 based on the figures and description of the holotype (Martin et al., 2012); characters 259 and 263-264 were scored based on the same.

Wahlisaurus massarae: Scoring for character 48 was corrected.

Leptonectes moorei: rescored for character 32, 233 based on pers. observ. of the holotype material.

Eurhinosaurus longirostris: Characters 20, 36, 53, 167 rescored and character 97 scored based on pers. observ. of specimens at the SMNS.

Excalibosaurus costini: Character 249 (number of phalanges) rescored based on the holotype specimen, characters 167, 217 rescored based on McGowan (2003).

Malawania anachronus: Characters 152, 219, 233 scored based on morphology illustrated in Fischer et al. (2013).

Stenopterygius quadriscissus: Characters 5, 9, 20, $32,44,61,87,152,233$ rescored based on pers. observ; character 82 rescored based on pers. observ.

Stenopterygius triscissus: Characters 5, 20, 152 rescored based on pers. observ; character 82 scored based on pers. observ.
Stenopterygius uniter: Characters 5, 9, 20, 152, 241 rescored based on pers. observ; character 82 rescored based on pers. observ.

Stenopterygius aaleniensis: Scoring of character 241 changed to '?' as the metacarpal row is not preserved in this taxon; character 5 (subnarial process) also rescored based on pers. observ.

Chacaicosaurus cayi: Characters 233, 247-248 rescored based on Fernández (1994).

Ophthalmosaurus icenicus: Character 41 rescored as present, based on the separation of the postfrontal from the parietal in dorsal view by a process of the frontal.

Caypullisaurus bonapartei: Scoring for character 247-248 changed, as manual metacarpal $V$ is present in these taxa (Fernández, 2001).

Arthropterygius chrisorum: Character 177 changed to '?' as the caudal region is not well-enough preserved to evaluate this character.

Paraophthalmosaurus kabanovi: Scoring for character 247 changed to ? because the limb is incompletely preserved in this specimen.

Muiscasaurus catheti: rescored as '?' for characters 11-12, since the maxilla-lacrimal suture is unclear.

Sveltonectes insolitus was rescored for character 227.

\section{REFERENCES}

Fernández, M.S. 1994. A new long-snouted ichthyosaur from the Early Bajocian of Neuquén Basin (Argentina). Ameghiniana, 31:291-297.

Fernández, M.S. 2001. Dorsal or ventral? Homologies of the forefin of Caypullisaurus (Ichthyosauria: Ophthalmosauria). Journal of Vertebrate Paleontology, 21:515-520.

Fischer, V., Appleby, R.M., Naish, D., Liston, J., Riding, J.B., Brindley, S., and Godefroit P. 2013. A basal thunnosaurian from Iraq reveals disparate phylogenetic origins for Cretaceous ichthyosaurs. Biology Letters, 9:20130021. https://doi.org/10.1098/rsbl.2013.0021

Lomax, D.R., and Massare, J.A. 2018. A second specimen of Protoichthyosaurus applebyi (Reptilia: Ichthyosauria) and additional information on the genus and species. Paludicola, 11:164-178.

Lomax, D.R., Massare, J.A., and Evans, M. 2019a. New information on the skull roof of Protoichthyosaurus (Reptilia: Ichthyosauria) and intraspecific variation in some dermal skull elements. Geological Magazine. https://doi.org/10.1017/S0016756819001225

Lomax, D.R., Porro, L.B., and Larkin, N.R. 2019b. Descriptive anatomy of the largest known specimen of Protoichthyosaurus prostaxalis (Reptilia: Ichthyosauria) including computed tomography and digital reconstruction of a three-dimensional skull. PeerJ 7: e6112. https:// doi.org/10.7717/peerj.6112

Lomax, D.R., Massare, J.A., and Mistry, R.T. 2017. The taxonomic utility of forefin morphology in Lower Jurassic ichthyosaurs: Protoichthyosaurus and Ichthyosaurus. Journal of Vertebrate Paleontology 37:e1361433. https://doi.org/10.1080/02724634.2017.1361433 
Maisch, M.W., and Matzke, A.T. 2000. The Ichthyosauria. Stuttgarter Beiträge zur Naturkunde Serie B (Geologie und Paläontologie), 298:1-159.

Martin, J.E., Fischer, V., Vincent, P., and Suan, G. 2012. A longirostrine Temnodontosaurus (Ichthyosauria) with comments on Early Jurassic ichthyosaur niche partitioning and disparity. Palaeontology, 55:995-1005. https://doi.org/10.1111/j.1475-4983.2012.01159.x

Maxwell, E.E., Cortés, D., Patarroyo, P., and Parra Ruge, M.L. 2019. A new specimen of Platypterygius sachicarum (Reptilia: Ichthyosauria) from the Early Cretaceous of Colombia and its phylogenetic implications. Journal of Vertebrate Paleontology, 39: e1577875. https:// doi.org/10.1080/02724634.2019.1577875

McGowan, C. 1979. A revision of the Lower Jurassic ichthyosaurs of Germany with descriptions of two new species. Palaeontographica Abt. A, 166:93-135.

McGowan, C. 2003. A new specimen of Excalibosaurus from the English Lower Jurassic. Journal of Vertebrate Paleontology, 23:950-956.

Melmore, S. 1930. A description of the type-specimen of Ichthyosaurus crassimanus, Blake (Owen MS.). Annals and Magazine of Natural History Series 10, 6:615-619.

Moon, B.C. 2017. A new phylogeny of ichthyosaurs (Reptilia: Diapsida). Journal of Systematic Palaeontology, 0:1-27. https://doi.org/10.1080/14772019.2017.1394922

Motani, R. 1999. Phylogeny of the Ichthyopterygia. Journal of Vertebrate Paleontology, 19:473496. 


\section{APPENDIX 3.}

Character list, copied directly from Moon (2017). Text in red corresponds to changes to the original character list that were introduced in Maxwell et al. (2019); text in blue indicates characters that were modified for the current study (characters 50, 165-166 only). See Appendix 2 for discussion and references. Characters 100,107, 153, 166, and 219 are treated as ordered.

\section{Skull}

Character 1 Snout - extremely slender premaxillary segment, $<1 / 4$ the maximum lateral width of the posterior of the skull: (0) absent (1) present (Motani 1999c, character 34). This is modified from Motani's (1999c) character 34 by defining a specific boundary of 'slender'. Motani's original character separates several taxa, especially his 'Eurhinosauria'. To maintain this distinction this character is defined as the width of the snout where the premaxillae exclude the nasals from dorsal view - the nasals anteriormost dorsal exposure - compared to the maximum width of the post-narial skull.

Character 2 Premaxilla - supranarial process: (0) present (1) absent (modified from Maisch and Matzke 2000b, character 9; and Maxwell 2012, character 1).

Character 3 Premaxilla - size of supranarial process: (0) large, extending $>1 / 3$ of the external narial length (1) small, extending $<1 / 3$ of the external narial length (modified from Maisch and Matzke 2000b, character 9; and Maxwell 2012, character 1).

Character 4 Premaxilla - subnarial process: (0) absent (1) present (modified from Maisch and Matzke 2000b, character 10; and Maxwell 2012, character 1).

Character 5 Premaxilla - size of the subnarial process: (0) small, extending $<1 / 3$ of the external narial length (1) large, extending $>1 / 3$ of the external narial length (modified from Maisch and Matzke 2000b, character 10; and Maxwell 2012, character 1).

Character 6 Premaxilla-palatine - contact in ventral view: (0) absent (1) present, relatively broad (Druckenmiller and Maxwell 2010, character 15).

Character 7 Maxilla - reduction: (0) absent, $\geq 1 / 2$ of the length of the snout (1) present, $<1 / 2$ the length of the snout (modified from Sander et al. 2011, character 106). The reduction of the maxilla is defined more specifically than Sander et al.'s (2011) character 106. While this is defined relative to the length of the snout as a whole, the dorsoventral exposure and contribution should also be considered (see character 9 ).

Character 8 Maxilla - bearing teeth: (0) present (1) absent. See character 7 .
Character 9 Maxilla - location of the laterally exposed greatest dorsoventral extent: (0) posterior to the external naris (1) ventral or anterior to the external naris (modified from Druckenmiller and Maxwell 2010, character 4). State one has been modified to include 'ventral to the external naris'.

Character 10 Maxilla - length of the premaxillary process: (0) short, extends approximately one or less narial lengths anterior to the external naris (1) long, extends approximately 1.5 or more narial lengths anterior to the external naris (Maxwell 2012, character 2).

Character 11 Maxilla - postnarial process exposed laterally: (0) present (1) absent (modified from Maisch and Matzke 2000b, character 11). The postnarial process of the maxilla is a dorsal extension of the maxilla posterior to the external naris, this is the processus postnarialis of Maisch and Matzke (1997a); it is equivalent to the dorsal lamina of Motani (1999c).

Character 12 Maxilla - size of the postnarial process exposure: (0) large (1) tiny (modified from Maisch and Matzke 2000b, character 11). Clarified that this refers to exposure of the postnarial process.

Character 13 Maxilla - size of the jugal process: (0) long, extending as far under the orbit as the lachrymal in lateral view (1) short, hidden in lateral view by the jugal (Maxwell 2012, character 3).

Character 14 Maxilla - contacts prefrontal: (0) absent (1) present (Maisch and Matzke 2000b, character 12).

Character 15 Maxilla - contacts external naris in external lateral view: (0) present (1) absent (modified from Fernández 2007a, character 2; after Fischer et al. 2011, character 9; and Fischer 2013, character 9).

Character 16 Nasal - anteroposterior extent of dorsal exposure in the prenarial rostrum: (0) substantial, over $40 \%$ (1) reduced, less than $40 \%$ (Maxwell 2012, character 4).

Character 17 Nasal posterior extent: (0) reaches back to the orbit (1) reaches distinctly over the orbit (Maisch and Matzke 2000b, character 14).

Character 18 Narial shelf: (0) absent (1) present (Jiang et al. 2006, character 4). This narial shelf is anterior to the external naris, bordered medially by the nasosupraorbital ridge (Jiang et al. 2006). 
Character 19 Nasal - borders external naris: (0) present (1) excluded (Sander 2000, character 7).

Character 20 Nasal - descending process on the interior posterior border of the nares: (0) absent (1) present (Fernández 2007a, character 2).

Character 21 Nasal-postfrontal - contact: (0) absent (1) present (modified from Nicholls and Manabe 2001, character 3).

Character 22 Nasal-postfrontal contact - size: (0) small (1) extensive, separating frontals and prefrontals in dorsal view (modified from Nicholls and Manabe 2001, character 3).

Character 23 Excavatio internasalis: (0) absent (1) present (Maisch and Matzke 2000b, character 16).

Character 24 Lachrymal - anterior extent: (0) reaches external naris (1) is excluded from the external naris by the dorsal process of the maxilla and/or the ventral process of the nasal (Sander 2000 , character 10$)$. The polarity of this character was reversed by Maxwell (2012, character 5 ).

Character 25 Lachrymal - numerous small-tomedium-sized nutritive foramina: (0) absent (1) present (Sander et al. 2011, character 111). This character refers to millimetre-size nutritive foramina that perforate the lachrymal and are only recorded in Shastasaurus.

Character 26 External nares - shape: (0) small, round to ovate (1) elongate (2) elongate and complexly lobate (Sander 2000, character 8). As this character defines shape, states one and two are considered suitably different that this should not be coded with reductive methods.

Character 27 External nares - orientation: (0) dorsolateral (1) lateral, scarcely visible in dorsal view (Motani 1999c, character 4).

Character 28 Jugal - shape: (0) triradiate (1) lunate or J-shaped (Motani 1999c, character 24). Compare this with character 31.

Character 29 Jugal - anterior margin shape: (0) tapering, running between the lachrymal and maxilla (1) broad and fanlike, covering a large area of the maxilla ventrolaterally (Druckenmiller and Maxwell 2010, character 6).

Character 30 Jugal - extent of anterior margin: (0) terminates posterior to the anterior end of the lachrymal (1) reaches or surpasses the anterior end of the lachrymal (Roberts et al. 2014, character 11).

Character 31 Jugal - dorsal ramus shape: (0) welldeveloped and strongly curved dorsally (1) poorly developed, jugal essentially straight (Maxwell 2012, character 8). This character is exclusive of character 28: poor development of the dorsal ramus does not preclude a J-shaped or triradiate jugal, although this may be less apparent.
Character 32 Jugal - contact between the postorbital process and the squamosal: (0) absent (1) present (Sander 2000, character 31).

Character 33 Jugal-quadratojugal - external contact: (0) absent (1) present (Motani 1999c, character 23). This was included as a new character by Roberts et al. (2014), who explicitly included the postorbital to separate the jugal and quadratojugal. Character 34 Jugal-quadratojugal notch - deep, forming a pronounced ventral emargination of the cheek: (0) present (1) absent (Jiang et al. 2005, character 24). This character is exclusive of character 79 as the ventral margin of the quadratojugal may be concave without forming a distinct emargination of the cheek.

Character 35 Prefrontal - dorsal exposure: (0) broadly exposed (1) present, but limited by the anterior process of the postfrontal and posterior process of the nasal (2) little to none (modified from Maxwell 2012, character 12).

Character 36 Prefrontal-external naris - contact: (0) absent (1) present (Druckenmiller and Maxwell 2010, character 7).

Character 37 Prefrontal-postfrontal - contact: (0) absent, the dorsal margin of the orbit is formed by the frontal (1) present, eliminating the frontal from the dorsal margin of the orbit (Motani 1999c, character 8). This character incorporates the revised interpretation of the skull of Ichthyosaurus and Stenopterygius (Motani 2005), but character states may have been revised. This also applies to subsequent skull roof characters.

Character 38 Prefrontal and postfrontal - high supraorbital crest: (0) absent (1) present (Maisch and Matzke 2000b, character 22).

Character 39 Frontals - dorsal view: (0) strongly convex at the anterior edge of the parietal foramen (1) flat to concave, overlapped by surrounding elements (Maxwell 2012, character 13). Overlapping by surrounding elements may be separated into another character, however, this has not clearly been seen to warrant this distinction.

Character 40 Frontal - location of the widest exposure: (0) located posteriorly (1) at nasal suture (Motani 1999c, character 15).

Character 41 Frontal - temporal process: (0) absent (1) present (Fischer et al. 2011, character 14).

Character 42 Frontal - participates in the supratemporal fenestra in dorsal view: (0) absent (1) present (modified from Druckenmiller and Maxwell 2010, character 9; and Fischer et al. 2011, character 14). This and the next character are separated for reductive coding. 
Character 43 Frontal - size of participation in the supratemporal fenestra: (0) small (1) extensive (modified from Druckenmiller and Maxwell 2010, character 9).

Character 44 Frontal and parietal - relative dorsal exposure size: $(0)$ frontal as large or larger than the parietal (1) frontal smaller than the parietal (Maisch and Matzke 2000b, character

17).

Character 45 Parietal - dorsal view contribution to the anterior margin of the supratemporal fenestra: (0) no contribution (1) minor contribution (2) large, almost completely excluding the postfrontal from contact (modified from Maxwell 2012, character 14).

Character 46 Parietal ridge: (0) absent (1) present (Motani 1999c, character 17).

Character 47 Parietal shelf - orientation (0) obliquely oriented; (1) horizontally oriented (modified from Nicholls and Manabe 2001, character 8).

Character 48 Parietal shelf - size: (0) large (1) reduced (modified from Nicholls and Manabe 2001, character 8).

Character 49 Parietals - separation of anterior processes of the right and left: (0) narrow, forming parietal fork, and frontal dorsally visible along the pineal foramen (1) widely open, resulting in absence of clear fork (Motani 1999c, character 19). This character may be coded as inapplicable if the anterior processes of the parietals contact (character 50).

Character 50 Parietals - location of the parietal foramen: (0) contact between the left and right parietals present anteriorly, frontal excluded from the parietal foramen; (1) on the frontoparietal suture; (2) entirely surrounded by the frontals (modified from Motani 1999c, character 19).

Character 51 Parietals - anterior fork elevated: (0) absent (1) present (Nicholls and Manabe 2001, character 10). This character is coded as inapplicable if no anterior parietal fork is present (character 49).

Character 52 Postparietals - additional bone separating the parietal and supratemporal: (0) absent (1) present (modified from Thorne et al. 2011, character 18).

Character 53 Parietal - size of the supratemporal process: (0) short (1) long (modified from Thorne et al. 2011, character 18).

Character 54 Parietal foramen - anteroposterior position: (0) approximately equal to the anterior edge of the supratemporal fenestra (1) well anterior to the anterior edge of the supratemporal fenestra (Maxwell 2012, character 15).
Character 55 Postfrontal - size of the posterior flange: $(0)$ delicate and narrow, not extending ventrally to the posterior orbital rim (1) robust and triangular, approaching posterior orbital rim (Druckenmiller and Maxwell 2010, character 12). The posterior flange on the postfrontal is found in all ichthyosaurs (Motani 1999c; Thorne et al. 2011), but the size of this varies (Druckenmiller and Maxwell 2010).

Character 56 Postfrontal-postorbital - size of contact: (0) narrow (1) broad (Roberts et al. 2014, character 16).

Character 57 Postfrontal-supratemporal - contact: (0) absent (1) present (Sander 2000, character 28). This is exclusive of character 55 as contact between the postfrontal and supratemporal may be made whether the posterior flange is large or small. Character 58 Postorbital - shape: (0) triradiate (1) lunate, without posterior process (Motani 1999c, character 11).

Character 59 Postorbital - size: (0) broad (1) narrow (Fernández 2007a, character 7).

Character 60 Postorbital - participates in the supratemporal fenestra: (0) present (1) absent (Motani 1999c, character 12).

Character 61 Postorbital-supratemporal - contact in external view: (0) present (1) absent (Maxwell 2012, character 6).

Character 62 Supratemporal - enlargement: (0) small, minimal posterior exposure (1) moderate, forming posterior border of the supratemporal fenestra (2) strongly enlarged, forms significant portion of the posterior and lateral borders to supratemporal fenestra and skull roof (modified from Sander 2000, character 26). The definitions for 'small' and 'enlarged' are clarified.

Character 63 Supratemporal - anterodorsal sheet overhanging the supratemporal fenestra: (0) absent (1) present (Maisch and Matzke 2000b, character 25).

Character 64 Supratemporal - size of the descending ramus: (0) pronounced, reaching at least half of the total height of the quadrate (1) reduced, a small process medial to the quadrate articulation (Maxwell 2012, character 17).

Character 65 Supratemporal-stapes - contact: (0) absent (1) present (Fischer et al. 2013, character 52).

Character 66 Sagittal eminence: (0) present (1) absent (Fischer et al. 2011, character 13).

Character 67 Supratemporal - orientation of parietal ramus in dorsal view (0) oblique, (1) horizontal. This character may not be independent from the 
orientation of the parietal shelf, but can be scored in the absence of a clear parietal shelf.

Character 68 Supratemporal - relative anterior extent of the lateral and parietal rami in dorsal view (0) subequal, (1) lateral ramus extending much further anteriorly.

Character 69 Squamosal: (0) present (1) absent. This character is added, and characters 70 to 72 are modified, and which may be coded as inapplicable, for reductive coding.

Character 70 Squamosal - shape: (0) triangular (1) squared (Fischer et al. 2011, character 16).

Character 71 Squamosal - posterior descending process: (0) absent (1) present (modified from Fernández 2007a, character 4). The absence of the squamosal is coded separately (character 69).

Character 72 Squamosal - participates in supratemporal fenestra: (0) present (1) excluded by supratemporal and/or postfrontal (Nicholls and Manabe 2001, character 6).

Character 73 Supratemporal fenestrae - width in dorsal aspect: (0) posterior half narrower than anterior half (1) anterior and posterior halves approximately equal in width (Druckenmiller and Maxwell 2010, character 11).

Character 74 Anterior terrace of the supratemporal fenestra: (0) absent (1) present (modified from Motani 1999c, character 14).

Character 75 Anterior terrace of the supratemporal fenestra - extent: (0) small, reaching the posterior part of the frontal anteriorly (1) large, reaching the nasal anteriorly (modified from Motani 1999c, character 14). See character 74 .

Character 76 Skull roof - posterior margin indented in dorsal view: (0) deep (1) moderate (Maisch and Matzke 2000b, character 27).

Character 77 Quadratojugal - location of the main body: (0) laterally (1) posteriorly (Maisch and Matzke 2000b, character 28).

Character 78 Quadratojugal - exposure: (0) broad in lateral view (1) narrow and most extensively exposed in posterior view (Maxwell 2012, character 8).

Character 79 Quadratojugal - shape of the ventral edge: (0) concave (1) ventral edge straight or entirely covered by the jugal (Maxwell 2012, character 9). See also character 34.

Character 80 Quadratojugal - distinctly offset quadrate process: (0) present (1) absent (Maisch and Matzke 2000b, character 29).

Character 81 Quadrate - dorsal articulation location: (0) enclosed laterally by the squamosal (1) articulates dorsomedially with the supratemporal only (Maxwell 2012, character 11). This character may be coded as inapplicable if the squamosal is absent (character 69), although this implies state (1).

Character 82 Quadrate - location of the stapedial facet on the posterior surface: (0) ventral half (1) dorsal half (Druckenmiller and Maxwell 2010, character 21).

Character 83 Orbit - shape of the anterior margin: (0) irregular (1) regularly rounded (2) angled (modified from Maisch and Matzke 2000b, character 23). The additional state 'angled' is added for the condition in e.g. Cryopterygius kristiansenae.

Character 84 Postorbital skull - length compared to orbital diameter: $(0)>1 / 3(1)<1 / 3$ (Jiang et al. 2005, character 7).

Character 85 Cheek - orientation: (0) mostly lateral (1) largely posterior (Motani 1999c, character 25).

Character $\mathbf{8 6}$ Interpterygoidal vacuity: (0) present (1) absent (modified from Motani 1999c, character 27). Other characters referring to a 'closed palate' (Jiang et al. 2005, character 12) and exposure of the basis cranii (Maisch and Matzke 2000b, character 44) are included within this. This character is modified into a simple presence/absence dichotomy.

Character 87 Palatine - contributes to subtemporal fenestra: (0) posteriorly forms anterior edge (1) posteriorly excluded from the subtemporal fenestra (Maxwell 2012, character 25).

Character 88 Pterygoid - transverse flange: (0) well-developed (1) poorly developed (modified from Motani 1999c, character 26). The development and orientation of the transverse flange of the pterygoid are separated for reductive coding (characters 88 and 89 ).

Character 89 Pterygoid - orientation of the transverse flange: (0) anterolateral (1) posterolateral (modified from Motani 1999c, character 26). See character 88.

Character 90 Pterygoid - posteromedial process: (0) present (1) absent (Maisch and Matzke 2000b, character 35).

Character 91 Vomer - number of dorsal processes: (0) one (1) two (Druckenmiller and Maxwell 2010, character 17). The vomer, particularly dorsally, is poorly known; while this character is included, its coding completeness is low.

Character 92 Epipterygoid - ossified: (0) present (1) absent.

Character 93 Basis cranii - largely formed by: (0) parasphenoid (1) basisphenoid (Maisch and Matzke 2000b, character 41). 
Character 94 Basioccipital - shape of the condyle: (0) flat or slightly concave (1) hemispherical (Motani 1999c, character 31).

Character 95 Basioccipital - notochordal pit on the condylar surface: (0) absent (1) present. See character 96.

Character 96 Basioccipital - location of notochordal pit on the condylar surface: (0) central (1) dorsal.

Character 97 Basioccipital peg: (0) present (1) absent (Fischer et al. 2011, character 20).

Character 98 Basioccipital - prominent ventral tubers separated by a deep notch: (0) present (1) absent (modified from Maxwell 2012, character 24). This character has been simplified to presence/absence.

Character 99 Basioccipital - extracondylar area: (0) present (1) absent. This character is added as, in some taxa, the extracondylar area may be entirely lost. This is incorporated into Fischer et al. (2013, character 20).

Character 100 Basioccipital - size of the ventral extracondylar area: (0) larger than the dorsoventral height of the condyle (1) smaller than the condyle but still extensive (2) reduced to a thin strip (Maxwell 2012, character 23). This is similar to Fischer et al. (2013, character 20). This character is treated as ordered.

Character 101 Basioccipital - contribution to the floor of the foramen magnum: (0) absent, excluded by the exoccipitals (1) present, the portion contributing being flat, or concave, and covered in finished bone (Maxwell 2012, character 21).

Character 102 Parabasisphenoid - base of basipterygoid processes in dorsal or ventral view: (0) offset and anteroposteriorly narrow, much less than half the anteroposterior length of the parabasisphenoid (1) markedly expanded, forming approximately $50 \%$ or more of the anteroposterior length of the parabasisphenoid.

Character 103 Carotid foramen - pairing: (0) paired (1) unpaired (modified from Maisch and Matzke 2000b, character 42; after Maxwell 2010, character 10). These two characters are joined, as they are slightly different versions of each other.

Character 104 Carotid foramen - location: (0) basioccipital and (1) parabasisphenoid (modified from Maisch and Matzke 2000b, character 42; after Maxwell 2010, character 10).

Character 105 Parasphenoid - shape of the base of the cultriform process: (0) wide, gently grading into the basal plate (1) distinctly narrowed, well offset from the basal plate (Maisch and Matzke $2000 \mathrm{~b}$, character 43 ).
Character 106 Parabasisphenoid - shape in dorsal or ventral view: (0) anterior edge (including basipterygoid processes) less than $2 / 3$ as long as posterior edge (1) anterior and posterior edges similar in length; (2) posterior edge less than $2 / 3$ as long as anterior edge.

Character 107 Parabasisphenoid - location of the carotid foramen: (0) opening near the middle of the ventral surface, (1) opening on the posterior third of the ventral surface, (2) opening on the posterior surface [treated as ordered] (modified from Maisch and Matzke 2000b, character 42; after Maxwell 2010, character 10). See characters 103 and 104. In cases where the carotid foramen is on the basioccipital rather than the parabasisphenoid (character 104), character 107 is coded as inapplicable.

Character 108 Opisthotic - shape of the paraoccipital process: (0) short and robust (1) elongate and slender (Fischer et al. 2012, character 20).

Character 109 Supraoccipital - orientation of the exoccipital processes: (0) parallel (1) divergent (Maxwell 2012, character 19).

Character 110 Exoccipital - contribution to foramen magnum: (0) exoccipitals make up the largest lateral contribution (1) supraoccipital contribution almost equal to that of exoccipitals (Maxwell 2012, character 20).

Character 111 Stapes - size of the proximal head: (0) slender, much smaller than opisthotic proximal head (1) massive, as large or larger than opisthotic (Fischer et al. 2011, character 21).

Character 112 Stapes - relative size of heads: (0) lateral head less robust than the medial head (1) both medial and lateral heads robust (Maxwell 2012, character 18).

Character 113 Stapes - size of shaft in adults: (0) thick (1) slender and gracile (Roberts et al. 2014, characters 25).

Character 114 Lower jaw: (0) well developed (1) reduced relative to lower jaw (Maxwell 2012, character 26).

Character 115 Lower jaw - development: (0) normal (1) slender, reduced in diameter (Sander et al. 2011, character 108).

Character 116 Lower jaw - ventral margin in lateral view: (0) straight, or nearly so (1) markedly concave approximately ventral to the external nares (modified from Sander 2000, character 37).

Character 117 Dentary - labial shelf: (0) absent (1) present (Jiang et al. 2006, character 14).

Character 118 Surangular - makes up most of the posterior lateral surface of the lower jaw: (0) absent 
(1) present (Maisch and Matzke 2000b, character 38).

Character 119 Surangular - dorsal (paracoronoid) process just anterior to the jaw articulation: (0) absent (1) present (Sander 2000, character 42).

Character 120 Angular - extent of anterior lateral exposure: (0) much smaller than the surangular's exposure (1) extensive, at least as high and anteriorly as the surangular's exposure (modified from Motani 1999c, character 32; after Fischer et al. 2011, character 22; and Maxwell 2012, character 28).

Character 121 Angular - extent of posterior lateral exposure: (0) minimal, covers less than half of the lateral surface of the retroarticular process (1) extensive, surangular exposure reduced to a thin strip on the lateral surface of the retroarticular process (Maxwell 2012, character 29).

Character 122 Splenial - participation in the mandibular symphysis: (0) more extensive than the dentary (1) present but restricted to the posterior half (Maxwell 2012, character 27).

Character 123 Coronoid - ossified: (0) present (1) absent (modified from Maisch and Matzke 2000b, character 45). This character is separated for reductive coding (see character 124).

Character 124 Coronoid - shape: (0) laterally flattened (1) narrow and elongate (modified from Maisch and Matzke 2000b, character 45). May be coded as inapplicable if the coronoid is not present/ ossified (character 123).

Character 125 Coronoid process: (0) flat (1) elevated (2) drawn into a pointed process (modified from Sander 2000, character 41). This refers to the true process on the coronoid, so may be coded as inapplicable if this is not present/ossified (character 123).

Character 126 Lower jaw glenoid - deeply excavated: (0) absent (1) present (Sander 2000, character 43).

Character 127 Articular - transverse width: (0) wide with dorsally deeply concave retroarticular process (1) narrow (Maisch and Matzke 2000b, character 47).

Character 128 Teeth: (0) present (1) absent (modified from Maisch and Matzke 2000b, character 4; after Fischer et al. 2011, character 4; and Sander et al. 2011, character 109). The presence/-absence of teeth is separated for reductive coding alongside character 129; subsequent dentition characters may become inapplicable in this case.

Character 129 Dentition - complete, well-developed dentition retained in adults: (0) present (1) strongly reduced (modified from Maisch and
Matzke 2000b, character 4; after Fischer et al. 2011, character 4; and Sander et al. 2011, character 109). This character is separated from edentulism as it refers to the size and number of teeth (character 128).

Character 130 Dentition - tooth implantation after Motani (1997a): (0) subthecodont (1) thecodont (2) aulacodont (modified from Sander 2000, character 52). Here, ankylosed and ichthyosaurian thecodonty are separated into separate characters (character 131).

Character 131 Dentition - bony fixation: (0) present (1) absent (Motani 1999c, character 43).

Character 132 Plicidentine: (0) absent (1) present (Motani 1999c, character 36).

Character 133 Dentition - number of tooth rows: (0) one (1) two (2) irregular pavement (Sander 2000, character 50).

Character 134 Upper dental groove: (0) absent (1) present (modified from Motani 1999c, character 41). Motani's (1999c) characters 41 and 42 have each been separated to form characters 134 to 137 by reductive coding. These are not excluded by edentulism (character 128): the dental groove may be retained.

Character 135 Upper dental groove - location: (0) throughout jaw margin (1) only anteriorly (modified from Motani 1999c, character 41). This character may be inapplicable if the upper dental groove is absent (character 134).

Character 136 Lower dental groove: (0) absent (1) present (modified from Motani 1999c, character 42). See character 134.

Character 137 Lower dental groove - location: (0) throughout jaw margin (1) only anteriorly (modified from Motani 1999c, character 42). This character may be inapplicable if the lower dental groove is absent (character 136).

Character 138 Dentition - number of maxillary positions ventral to the jugal: (0) less than three (1) four or more (Druckenmiller and Maxwell 2010, character 16).

Character 139 Palatine teeth: (0) present (1) absent.

Character 140 Pterygoidal teeth: (0) present (1) absent (Motani 1999c, character 44).

Character 141 Dentition - replacement: (0) irregular (1) regular (Sander 2000, character 51).

Character 142 Dentition - position of replacement teeth to the pulp cavity of the predecessor: (0) outside (1) inside (Motani 1999c, character 35).

Character 143 Dentition - ornamentation of the enamel: (0) prominent ridges and grooves (1) thin 
and smooth (2) thick and bumpy (Maxwell 2012, character 30).

Character 144 Dentition - shape of the root crosssection in adults: (0) rounded (1) quadrangular (modified from Fischer et al. 2011, character 3; after Fischer et al. 2012, character 3).

Character 145 Dentition - dentine infolding (0) striations not externally visible basal to the crown in the apical third of the root; (1) forming prominent grooves and ridges basal to the crown in the apical third of the root.

Character 146 Dentition - dentine infolding (0) creating clear externally visible striations in the basal half of the root in functional teeth, (1) completely obscured by cellular cementum.

Character 147 Dentition - definition of the base of the enamel layer: (0) poorly defined or invisible (1) well defined and precise (Fischer et al. 2011, character 2).

Character 148 Dentition - horizontal section of the tooth crown: (0) circular (1) mesiodistally compressed (2) laterally compressed (modified from Motani 1999c, character 37). This has been restricted to the tooth crown only.

Character 149 Dentition - shape of the posterior tooth crown: (0) conical (1) rounded (2) flat (Motani 1999c, character 39).

\section{Postcranial axial skeleton}

Character 150 Atlas pleurocentrum - shape: (0) anteriorly convex (1) deeply concave (Maisch and Matzke 2000b, character 49).

Character 151 Atlas-axis: (0) separate (1) co-ossified in adults (Maisch and Matzke 2000b, character 50).

Character 152 Atlas-axis - neural spines: (0) completely overlapping, may be fused (1) functionally separate, never fused (Druckenmiller and Maxwell 2010, character 26).

Character 153 Presacral vertebrae - number: (0) $\mathrm{n}<40$ (1) $40 \leq \mathrm{n}<55$ (2) $55 \leq \mathrm{n}$ (modified from Motani 1999c, character 95). [treated as ordered]

Character 154 Central facets: (0) bulging (1) central face straight-sided (modified from Sander 2000 , character 58).

Character 155 'Cervical' vertebrae - diapophysisneural arch contact extent: (0) up to middle dorsal region (1) anterior dorsal region (Fischer et al. 2011, character 23).

Character 156 'Cervical' vertebrae - centrum to neural arch height: $(0)<2(1) \leq 2$ (modified from Sander 2000, character 61). This has been simplified to a dichotomy.
Character 157 'Cervical' centra - bicipital rib facet: (0) absent (1) present (Motani 1999c, character 99).

Character 158 Postcervical to presacral centra number of rib articulations: (0) holocephalous throughout (1) dicephalous in posterior dorsal and anterior caudal region, remainder holocephalous (2) dicephalous throughout (Nicholls and Manabe 2001, character 38).

Character 159 Dorsal centra - increase in height from anterior to posterior: (0) absent (1) present (Sander 2000, character 55).

Character 160 Anterior dorsal neural spine shape: (0) normal (1) narrow, high and straight (Motani 1999c, character 102).

Character 161 Anterior dorsal/thoracic zygapophyses - pairing: (0) paired (1) bilobate (2) unpaired (modified from Maisch and Matzke 2000b, character 51). The additional state 'bilobate' is added to separate when the two zygapophyses meet medially.

Character 162 Anterodorsal centra - rib facet position: (0) confluent with anterior face in at least some centra (1) not confluent in any (Motani 1999c, character 101).

Character 163 Anterodorsal centra - synapophysis shape: (0) symmetrical, hourglass-shaped (1) asymmetrical with irregular swellings and constrictions (modified from Nicholls and Manabe 2001, character 40).

Character 164 Posterior dorsal centra - outline: $(0) \leq 3.5 \times$ high as long $(1) \leq 4 \times$ high as long (Fischer et al. 2011, character 24). These codings are the reverse of Maxwell (2010, character 15), but direction is defined by the outgroup to the clade where the state changes.

Character 165 Sacrum: (0) present, at least one morphologically differentiated sacral rib can be observed (1) absent, no truly sacral ribs are present (Motani, 1999 character 104 [part]).

Character 166 Sacral ribs: (0) two with distal expansion, (1) one with distal expansion, (2) present and morphologically distinct [see character 165] but no distal expansion present. Is inapplicable when sacrum is absent/undifferentiated (character 165). [treated as ordered]

Character 167 Tail - length relative to precaudal body: (0) longer (1) shorter (Maisch and Matzke 2000b, character 65; Fischer et al. 2013, character 33).

Character 168 Tail - lunate tail fin: (0) none (1) well-developed (Maisch and Matzke 2000b, character 66). 
Character 169 Caudal peak: (0) absent (1) present (Motani 1999c, character 96). This character is separate from character 168: the caudal peak is interpreted as an early modification of the tail to an aquatic lifestyle, with development of a tail fin (Motani 1999c; McGowan \& Motani 2003).

Character 170 Caudal centra - mid-region height change: (0) gradual decrease (1) increase (2) sudden decrease (Motani 1999c, character 98).

Character 171 Caudal centra - elongation: (0) elongate (1) short (Maisch and Matzke 2000b, character 59).

Character 172 Anterior caudal vertebrae - neural arch to centrum height: $(0)<2(1) \leq 2$ (modified from Sander 2000, character 63).

Character 173 Anterior to middle caudal centra spinous process shape: $(0)$ very long and slender (1) short and wide (Maisch and Matzke 2000b, character 61).

Character 174 Middle caudal centra - neural spine inclination: (0) distinctly anterior (1) vertical or posterior (Maisch and Matzke 2000b, character 60).

Character 175 Tail fin centra - shape: (0) strongly laterally compressed (1) as wide as high (Maxwell 2010, character 16).

Character 176 Chevrons - ossified: (0) present (1) absent.

Character 177 Chevrons: (0) present throughout caudal region (1) absent in apical region.

Character $178 \mathrm{Rib}$ - cross-sectional shape at midshaft: (0) oval or with posterior groove (1) figure-ofeight (2) round with anterior and posterior flanges (3) (modified from Sander 2000, character 73). State three is added to code for the outgroup Hupehsuchus nanchangensis.

Character 179 Gastralia - V-shaped median element: (0) present (1) absent (modified from Sander 2000, character 75).

Character 180 Gastralia - lateral elements: (0) one lateral element per side (1) two lateral elements per side (modified from Sander 2000, character 75).

\section{Appendicular skeleton}

Character 181 Interclavicle - shape: (0) cruciform (1) triangular (1) T-shaped (Motani 1999c, character 45).

Character 182 Clavicle - expanded medial flange: (0) present (1) absent, clavicle slender and narrow medially (Maisch and Matzke 2000b, character 68). Character 183 Coracoid - shape: (0) mediolaterally wider than anteroposteriorly long (1) approximately equidimensional (2) anteroposteriorly longer than mediolaterally wide (Maxwell 2012, character 32).

Character 184 Coracoid - medial margin: (0) wellrounded (1) straight symphysis (Maisch and Matzke 2000b, character 73).

Character 185 Coracoid - anterior notch: (0) present (1) absent (modified from Maxwell 2012, character 33).

Character 186 Coracoid - posterior notch: (0) present (1) absent (modified from Maxwell 2012, character 34).

Character 187 Coracoid - lengths of anterior and posterior extensions: (0) anterior extension longer than posterior (1) reduced anterior extension (Maisch and Matzke 2000b, character 74).

Character 188 Coracoid - anteromedial process: (0) present (1) absent (Fischer et al. 2011, character 29).

Character 189 Coracoid - glenoid and scapular facet sizes: (0) very small (1) enlarged (Maisch and Matzke 2000b, character 72).

Character 190 Coracoid - medial facet for the scapula: (0) absent (1) present (Arkhangelsky \& Zverkov 2014, character 52).

Character 191 Scapula - anterior expansion proximally: (0) present (1) absent (modified from Maxwell 2012, character 31). Maxwell et al.'s (2012) character is modified to presence/- absence of acromion process, with anterior expansion (states 1 and 2) separated into character 192.

Character 192 Scapula - prominent acromion process: (0) present (1) absent (modified from Maxwell 2012, character 31).

Character 193 Scapula - shape of the anterodorsal margin: (0) fan-shaped (1) emarginated (2) straight (Motani 1999c, character 46).

Character 194 Scapula - size of the glenoid contribution: (0) at least as large as the coracoid facet (1) markedly smaller than the coracoid facet (Fischer et al. 2012, character 27).

Character 195 Scapula - posterior process: (0) distinct and large (1) reduced (Maisch and Matzke 2000b, character 71).

Character 196 Scapula - blade shaft: (0) absent (1) present at least proximally (Motani 1999c, character 47).

Character 197 Scapula - angle subtended by the axis and glenoid facet: (0) nearly parallel (1) $60^{\circ}$ or more (Motani 1999c, character 48).

Character 198 Humerus - differentiated and offset proximal head: (0) present (1) absent (Maisch and Matzke 2000b, character 75).

Character 199 Humerus - anterior margin: (0) straight, convex (1) with small central notch (2) 
markedly concave (modified from Maisch and Matzke 2000b, character 77).

Character 200 Humerus - anterior flange: (0) absent (1) present (modified from Motani 1999c, character 53).

Character 201 Humerus - anterior flange size: (0) large, complete (1) reduced proximally (modified from Motani 1999c, character 53). See character 200.

Character 202 Humerus - relative width at midshaft, exclusive of anterior flange: (0) more than twice as proximodistally long as anteroposteriorly wide (1) approximately equidimensional (Motani 1999c, character 54).

Character 203 Humerus - dorsal trochanter: (0) none or incipient (1) well-developed (Maisch and Matzke 2000b, character 78).

Character 204 Humerus - protruding deltopectoral crest: (0) absent (1) present (modified from Fischer et al. 2011, character 31; after Fischer et al. 2013, character 39).

Character 205 Humerus - development of protruding deltopectoral crest: (0) normal (1) large, matching the dorsal trochanter in height, and bordered by concave areas (modified from Fischer et al. 2011, character 31; after Fischer et al. 2013, character 39). See character 204.

Character 206 Humerus - relative anteroposterior width in dorsal view, excluding dorsal and ventral processes: (0) distal end wider than proximal (1) approximately equal or proximal end wider than distal (Fischer et al. 2011, character 32).

Character 207 Humerus - plate-like dorsal ridge: (0) absent (1) present (Druckenmiller and Maxwell 2010, character 31).

Character 208 Humerus - position of distal facets: (0) not terminal (1) terminal (modified from Motani 1999c, character 52).

Character 209 Humerus - relative size of radial and ulnar facets: (0) radial facet is larger than the ulnar facet (1) radial and ulnar facets approximately equal size (modified from Motani 1999c, character 52). See character 208.

Character 210 Humerus - separation of radial and ulnar facets: (0) continuous (1) separated by notch (Maxwell 2012, character 36). This is coded as inapplicable in taxa where the radial and ulnar facets are separated by e.g. the intermedial facet.

Character 211 Humerus - ulnar facet deflected posterodistally, distal facing radial facet: (0) absent (1) present (Fischer et al. 2012, character 34).

Character 212 Humerus - tuberosity at the anterodistal extremity: (0) present (1) absent, acute angle (Fischer et al. 2013, character 44).
Character 213 Humerus - anterodistal facet for sesamoid: (0) absent (1) present (Motani 1999c, character 57).

Character 214 Humerus - posterodistal facet for sesamoid: (0) absent (1) present (Druckenmiller and Maxwell 2010, character 36).

Character 215 Humerus-intermedium - contact: (0) absent (1) present (Fernández 2007a, character 16).

Character 216 Forelimb - epipodial and metapodial shape: (0) flattened and plate-like (1) strongly thickened (Maisch and Matzke 2000b, character 94).

Character 217 Forelimb - notching of anterior face on leading edge elements [in adults]: (0) present (1) absent (Fischer et al. 2011, character 37).

Character 218 Forelimb - notching of posterior face on trailing edge elements [in adults]: (0) absent (1) present.

Character 219 Forelimb - number of postaxial 'complete' accessory digits: (0) none (1) one (2) two or more (Fischer et al. 2011, character 38). This character is treated as ordered. See also characters 217, 283 and 284.

Character 220 Epipodials - relative size of anterior and posterior element: (0) radius/tibia much larger than ulna/fibula (1) equal in size (modified from Nicholls and Manabe 2001, character 24).

Character 221 Epipodials - interosseous space between ulna and radius: (0) present (1) small foramen (2) absent (Sander 2000, character 87).

Character 222 Radius - proximodistal length to anteroposterior width: (0) longer than wide (1) wider than long (Motani 1999c, character 61).

Character 223 Ulna - posterior margin: (0) concave (1) notched (2) straight or convex (modified from Motani 1999c, character 62). See character 199.

Character 224 Ulna - anteroposterior width: (0) proximal end narrower than distal (1) about equal widths (Maisch and Matzke 2000b, character 87).

Character 225 Ulna - shape of the posterior surface: (0) rounded or straight and nearly as thick as the rest of the element (1) concave with a thin, blade-like margin (Fischer et al. 2012, character 36, 2013, character 45).

Character 226 Manual pisiform: (0) present (1) absent (Motani 1999c, character 67).

Character 227 Manual pisiform 2 (neomorph): (0) absent (1) present (Jiang et al. 2006, character 20).

Character 228 Intermedium: (0) present (1) absent (modified from Motani 1999c, character 66). 
Character 229 Intermedium-ulnare - relative size: (0) ulnare larger than intermedium (1) ulnare smaller than intermedium (modified from Motani 1999c, character 66). See character 228.

Character 230 Intermedium - location: (0) distal to the ulna (1) between radius and ulna (modified from Fernández 2007a, character 19).

Character 231 Intermedium - shape: (0) as wide or wider than long (1) longer than wide (modified from Jiang et al. 2006, character 22).

Character 232 Intermedium - proximal shape: (0) straight or notched (1) pointed (modified from Jiang et al. 2006, character 22).

Character 233 Intermedium - distal edge shape: (0) angular (1) flattened (Maxwell 2010, character 27).

Character 234 Intermedium - number of digits directly supported: (0) one (1) two (2) three (modified from Fischer et al. 2011, character 40). The intermedium must have substantial distal facets present for articulation with distal carpals, or contact a distal carpal over at least $30 \%$ of its proximal surface for a digit to be considered to be supported.

Character 235 Intermedium - size of distal facets: (0) subequal (1) one much larger than the other(s) (modified from Maxwell 2012, character 43).

Character 236 Ulnare - number of distal facets: (0) primarily supporting a single digit (1) a posteriorly oriented facet for articulation with metacarpal $\mathrm{V}$ at least half the length of the facet for mclV (Maxwell 2012, character 44).

Character 237 Distal carpal - number: (0) five (1) four (2) three (3) two (modified from Sander 2000, character 92). This refers only to 'true' distal carpals, and not accessory elements in the distal carpal row (after Motani 1999a).

Character 238 Distal carpal 1-metacarpal V - relative size: (0) much smaller (1) similar size or larger (modified from Maisch and Matzke 2000b, character 95). This may be coded as inapplicable if either element is not present.

Character 239 Distal carpals 2-3-distal carpal 5 relative size: (0) much smaller (1) of comparable size (Maisch and Matzke 2000b, character 96).

Character 240 Distal carpal 4-metacarpal V - relative size: (0) much smaller (1) comparable in size or larger (Maisch and Matzke 2000b, character 100).

Character 241 Manual digits - number of ossified elements in the metacarpal row: (0) four or fewer (1) five or more (Maxwell 2012, character 45).
Character 242 Manual preaxial accessory digit: (0) absent (1) present (Fischer et al. 2011, character 39).

Character 243 Manual digit $V$ reduction: (0) none (1) reduced to small floating elements (modified from Fischer et al. 2013, character 55). The absence of digit five is removed from this character as it is coded by the loss of metacarpal $\mathrm{V}$ (character 247).

Character 244 Manual metacarpal I: (0) present (1) absent (modified from Motani 1999c, character 68).

Character 245 Manual metacarpal I - shape: (0) elongate (1) semilunate or rounded (modified from Maisch and Matzke 2000b, character 97).

Character 246 Manual metacarpals II-IV - shape: (0) elongate cylinder (1) rounded (Maisch and Matzke 2000b, character 98).

Character 247 Manual metacarpal V: (0) present (1) absent (modified from Maisch and Matzke 2000b, character 99).

Character 248 Manual metacarpal $\mathrm{V}$ - posterior margin: (0) convex (1) straight or concave (modified from Maisch and Matzke 2000b, character 99).

Character 249 Manual phalanges - maximum number in a single digit: (0) five or less (1) six or more (modified from Motani 1999c, character 77).

Character 250 Proximal manual phalanges shape: (0) elongate or hourglass-shaped (1) mostly rounded (2) tightly packed rectangles/polygons (modified from Maisch and Matzke 2000b, character 102; after Fischer et al. 2011, character 42).

Character 251 Distal manual phalanges - shape: (0) elongate (1) rounded (Maisch and Matzke 2000b, character 101).

Character 252 Manual digital bifurcation: (0) absent (1) present in at least some individuals (modified from Fischer et al. 2011, character 43).

Character 253 Pelvic girdle - size: (0) normalsized (1) moderately reduced (2) strongly reduced (Sander 2000, character 103).

Character 254 llium - blade shape: (0) with thick shaft (1) plate-like (2) narrow and styloidal (Motani 1999c, character 80).

Character 255 llium - anteromedial prominence: (0) present (1) absent (Motani 1999c, character 81).

Character 256 Ischium-pubis - medial fusion: (0) absent (1) present (modified from Maxwell 2012, character 50).

Character 257 Ischium-pubis - lateral fusion: (0) absent (1) present (modified from Maxwell 2012, character 51). 
Character 258 Ischium and pubis - meet medially in well defined symphysis: (0) present (1) strongly convex medial margins (Maisch and Matzke 2000b, character 108).

Character 259 Ischium and pubis - relative size: (0) pubis larger than ischium (1) similar size or ischium larger (Maisch and Matzke 2000b, character 107).

Character 260 Ischium or ischiopubis - shape: (0) plate-like, flattened (1) rod-like (Fischer et al. 2011, character 45).

Character 261 Ischium - medial edge expansion: (0) great (1) little or none (Maxwell 2012, character 53).

Character 262 Ischium - acetabular contribution: (0) greater than pubis (1) subequal with pubis (Maxwell 2012, character 52).

Character 263 Pubis - obturator foramen: (0) present (1) absent (modified from Motani 1999c, character 84).

Character 264 Pubis - location of obturator foramen: (0) completely enclosed in pubis (1) mostly in pubis but open on one side (2) part of obturator fossa (Thorne et al. 2011, character 84).

Character 265 Pubis - distance between the obturator foramen[/incisure] and the pubic symphysis: (0) closer to the glenoid than the pubic symphysis (1) closer to the pubic symphysis than to the glenoid (2) obturator fossa open medially (modified from Maisch and Matzke 2000b, character 110).

Character 266 Femur - relative proximodistal length to anteroposterior width: $(0)$ much $(>2 x)$ longer than wide (1) shorter and wider, with distinct medial constriction (Sander 2000, character 110).

Character 267 Femur - prominent, ridge-like dorsal and ventral processes demarcated from the head and extending up to mid-shaft: (0) absent (1) present (Fischer et al. 2011, character 46).

Character 268 Femur - ventral process size relative to dorsal process: (0) smaller (1) same size or larger, more prominent (Roberts et al. 2014, character 52).

Character 269 Femur - wide distal blade: (0) present (1) absent, subequal proximal and distal widths (Fischer et al. 2013, character 61).

Character 270 Femur - anterodistal facet for anterior accessory epipodial element anterior to the tibia: (0) absent (1) present (Fischer et al. 2011, character 48).

Character 271 Femur - tibial facet size relative to fibular facet: (0) larger (1) subequal (Maisch and Matzke 2000b, character 112).
Character 272 Tibia - proximodistal length to anteroposterior width: (0) longer than wide (1) wider than long (Motani 1999c, character 90).

Character 273 Tibia - anterior margin: (0) concave (1) notched (2) straight or convex (modified from Motani 1999c, character 92). See character 199.

Character 274 Tibia - posterior margin: (0) concave (1) notched (2) straight or convex (modified from Motani 1999c, character 91). See character 199.

Character 275 Tibia - proximodistal length relative to more distal elements: (0) approximately twice as long (1) only slightly longer (Maxwell 2012, character 55).

Character 276 Tibia and fibula - relative size: (0) tibia larger than fibula (1) approximately equal (2) tibia proximodistally and anteroposteriorly smaller (Maxwell 2012, character 56).

Character 277 Tibia and fibula - proximal contact: (0) absent (1) present (modified from Motani 1999c, character 88; after Maxwell 2012, character 57).

Character 278 Fibula - anterior margin: (0) concave (1) notched (2) straight or convex (modified from Maxwell 2012, character 59). See character 199.

Character 279 Fibula - position relative to femur: (0) not fixed, mobile relative to the femur (1) much posterior (2) about the same level (Motani 1999c, character 93).

Character 280 Astragalus - position: (0) between tibia and fibula (1) distal to tibia (Druckenmiller and Maxwell 2010, character 48).

Character 281 Distal tarsals - number: (0) five (1) four (2) three (Sander 2000, character 112).

Character 282 Pedal digit 1: (0) present (1) absent (Motani 1999c, character 89).

Character 283 Hindlimb - notching on anterior of leading edge metapodials: (0) absent (1) present (Maxwell 2012, character 60). See also characters 217, 218 and 284.

Character 284 Hindlimb - notching on posterior of trailing edge metapodials: (0) absent (1) present.

Character 285 Pedal postaxial accessory digit: (0) absent (1) present (Fischer et al. 2011, character 50).

Character 286 Metatarsals - shape: (0) elongate or hourglass-shaped (1) shortened and rounded (2) polygonal (modified from Maisch and Matzke 2000b, character 118).

Character 287 Pedal phalanges - shape: (0) elongate or hourglass-shaped (1) rounded (2) polygonal (modified from Maisch and Matzke 2000b, character 119). See character 286. 


\section{APPENDIX 4.}

Character by taxon matrix for phylogenetic analysis (.nex). (Available in zipped file at https:// palaeo-electronica.org/content/2020/3078-revision-of-hauffiopteryx.) 